\title{
1 Structural basis of cowpox evasion of NKG2D immunosurveillance
}

3 Eric Lazear ${ }^{1,9,12}$, Michel M. Sun ${ }^{3,11,12}$, Xiaoli Wang ${ }^{1,2}$, Theresa L. Geurs ${ }^{3}$, Christopher A. Nelson ${ }^{1}$,

4 Jessica A. Campbell ${ }^{4,8}$, Danna Lippold ${ }^{3}$, Alexander S. Krupnick ${ }^{5,10}$, Randall S. Davis ${ }^{6}$, Leonidas

5 N. Carayannopoulos ${ }^{4,7}$, Anthony R. French ${ }^{1,3 *}$ and Daved H. Fremont ${ }^{1,2 *}$

7 Departments of Pathology \& Immunology ${ }^{1}$, Biochemistry \& Molecular Biophysics ${ }^{2}$, Pediatrics $^{3}$,

8 Internal Medicine ${ }^{4}$, and Surgery ${ }^{5}$ Washington University in St. Louis, St. Louis, Missouri, USA;

9 Departments of Medicine, Microbiology, and Biochemistry and Molecular Genetics ${ }^{6}$, University

10 of Alabama at Birmingham, Birmingham, AL 35294

11

$12 \quad{ }^{7}$ Current address: Celgene Pharmaceutical Company, Summit, NJ.

$13{ }^{8}$ Current address: Pfizer Inc., St. Louis, MO.

$14{ }^{9}$ Current address: Courier Therapeutics, Houston, TX.

$15{ }^{10}$ Current address: Department of Surgery, University of Virginia, Charlottesville, VA.

$16{ }^{11}$ Current address: Department of Ophthalmology, University of California, Los Angeles, CA.

1812 These authors contributed equally to this work

$22{ }^{*}$ Co-corresponding authors:

23 fremont@wustl.edu, phone: 314-255-6171, fax: 314-362-8888 french a@kids.wustl.edu, phone: 314-286-2885; fax: 314-286-2895 


\section{Abstract}

NKG2D is a key component of cytotoxic antitumor and antiviral responses. Multiple

4 viruses evade NKG2D recognition by blocking NKG2D ligand expression on infected cells. In

5 contrast, cowpox virus targets NKG2D directly by encoding a secreted antagonist,

6 Orthopoxvirus MHC Class I-like Protein (OMCP). We have previously reported that OMCP also

7 binds to the orphan receptor FcRL5 on innate B cells. Here, we demonstrate that mammalian-

8 derived, glycosylated OMCP binds NKG2D but not FcRL5. Cowpox viruses either lacking

9 OMCP, or expressing an NKG2D-binding deficient mutant, are significantly attenuated in wild

10 type and FCRL5-deficient mice but not NKG2D-deficient mice, demonstrating that OMCP is

11 critical in subverting NKG2D-mediated immunity in vivo. Next we determined the structure of

12 OMCP bound to human NKG2D. Despite a structure similar to that of host NKG2D ligands,

13 OMCP uses a drastically different orientation for NKG2D binding. The re-orientation of OMCP

14 is associated with dramatically higher affinity for human NKG2D and the targeted interface is

15 highly conserved in mammalian NKG2Ds, increasing the zoonotic potential of cowpox virus. We

16 also show that cell surface presented OMCP can trigger NKG2D effector functions equivalently

17 to host NKG2D ligands, demonstrating that NKG2D-mediated signaling requires clustering but is

18 insensitive to binding orientation. Thus, in contrast to TCR/MHC interactions, the docking

19 topology of NKG2D with its ligands does not appear to regulate its activation. 


\section{Author Summary}

Virally infected or tumor-transformed cells display NKG2D ligands (NKG2DLs) on their

4 cell surface, which activates NKG2D-bearing lymphocytes to kill the transformed cell.

5 Pathogens are known to counter this by blocking NKG2DL expression and/or surface display. In

6 contrast, some tumor cells cleave endogenous NKG2DLs creating soluble NKG2D antagonists.

7 Unlike other viral pathogens, cowpox virus uses a strategy analogous to cancer cells by

8 targeting NKG2D directly with a soluble, high affinity NKG2D-antagonist named OMCP. We

9 determined that OMCP's virulence in vivo is attributed to blocking NKG2D-mediated NK cell

10 responses with no apparent effect due to binding to other receptors or cell types. We have also

11 determined the crystal structure of cowpox OMCP bound to human NKG2D, revealing that

12 despite conservation of the ligand scaffolding with host NKG2DLs, the viral protein is engaged

13 with a radically altered orientation compared to all host NKG2DLs. Our structure provides key

14 insight into how OMCP binds with an $~ 5,000$-fold increased affinity compared to human

15 NKG2DLs and show that the OMCP binding site is exceptionally conserved among primates

16 and rodents, suggesting that the ability of OMCP to recognize this conserved interface

17 contributes to the broad zoonotic potential of cowpox virus. Finally, we show that cell

18 membrane-anchored OMCP can trigger equivalent NKG2D-mediated killing as host NKG2DLs,

19 demonstrating that NKG2D signaling is insensitive to ligand binding orientation. 


\section{Introduction}

Intracellular surveillance mediated by $\mathrm{MHC}$ class I $(\mathrm{MHCl})$ is a critical host immune

4 function and as such $\mathrm{MHCl}$ molecules are frequently targeted for destruction or intracellular

5 retention by viruses [1]. Many herpesviruses encode at least one protein that prevents the cell

6 surface expression of $\mathrm{MHCl}[1,2]$. However, this immune evasion strategy renders the infected

7 cell susceptible to NK cell-mediated lysis due to loss of inhibitory signals [3]. Viral infection also

8 leads to cell surface display of NKG2D ligands (NKG2DLs) recognized by the activating

9 receptor NKG2D, further predisposing the infected cell towards NK cell-mediated lysis.

10 Therefore, viruses that target $\mathrm{MHCl}$ expression often also sabotage NKG2D-mediated cell

11 responses by targeting NKG2DLs on infected cells [4-7].

$12 \quad$ NKG2DLs are not normally expressed on the cell surface but can be induced by cellular

13 stress [8]. The specific trigger for NKG2DL expression is not known, but NKG2DLs are

14 upregulated in response to several viral infections [9-12]. NKG2DLs comprise a large group of

15 proteins all recognized by NKG2D, despite having low sequence identity. NKG2DLs include the

16 MIC (A and B) and ULBP (1-6) families in humans as well as MULT1 and the RAE-1 ( $\alpha-\varepsilon)$ and

$17 \mathrm{H} 60$ (a-c) families in mice [13]. The redundancy in NKG2DLs is likely due to a combination of

18 tissue specific expression patterns of the ligands and the need to counter viral NKG2D evasion

19 strategies [14]. Many viruses have evolved mechanisms to inhibit the cell surface expression of

20 NKG2DLs as a means of interfering with NKG2D surveillance of viral infection. This strategy is

21 most apparent among $\beta$ - and $\gamma$-herpesviruses, in which four murine cytomegalovirus proteins

22 (m138, m145, m152, m155) [15-18], two human cytomegalovirus proteins (UL16, UL142) [19,

23 20] and one Kaposi's sarcoma-associated herpesvirus protein (K5) [21] have been

24 demonstrated to block NKG2DL surface expression. This evasion strategy is also found in RNA

25 viruses, as hepatitis C virus NS3/4a and human immunodeficiency virus Nef proteins also block

26 the expression of a subset of NKG2DLs [22, 23]. Additionally, human cytomegalovirus, herpes 
1 simplex virus type 1 and Epstein-Barr virus each also encode at least one miRNA that prevents

2 translation of MICB [24, 25]. Similarly, JCV and BKV polyoma viruses target ULBP3 with

3 miRNAs [26]. However, blocking NKG2DL expression on the infected cell is an imperfect

4 evasion strategy, since no single viral protein or miRNA has been shown to block the

5 expression of all NKG2DLs.

6 Like several herpesviruses, cowpoxvirus (CPXV) also sabotages $\mathrm{MHCl}$ expression.

7 CPXV expresses CPXV012 and CPXV203, two proteins that prevent TAP-mediated peptide

8 transport and $\mathrm{MHCl}$ trafficking to the cell surface, respectively [27-34]. Ectromelia virus, a

9 related orthopoxvirus, induces NKG2DL expression, and NKG2D is critical for the control of

10 ectomelia virus pathogensis [35]. Infection with another orthopoxvirus, monkeypox virus, leads

11 to dramatic expansion of NK cells but impaired NK cell function [36]. Together this suggests

12 that CPXV infected cells would be sensitive to NK cell-mediated lysis.

13 Unlike herpesviruses, CPXV does not target NKG2DLs. Instead this virus targets

14 NKG2D directly by encoding a competitive inhibitor of NKG2DLs, orthopoxvirus MHC class I-like

15 protein $(\mathrm{OMCP})[37,38]$. OMCP is a 152 residue protein that is secreted from infected cells and

16 antagonizes the NKG2D-mediated killing of NKG2DL-expressing target cells [37]. OMCP also

17 was reported to bind to $B$ cells via Fc-receptor like protein 5 (FcRL5) and to

18 monocyte/macrophages [39]. OMCP binds to murine NKG2D with an affinity equal or greater

19 than all tested murine NKG2DLs, and to human NKG2D with an affinity 5,000-fold higher than

20 human NKG2DLs [37, 38, 40, 41].

21 Despite their divergence in sequence identity, all known host NKG2DLs share common

22 structural features [42, 43]. NKG2DLs contain an MHCl-like platform domain composed of an

23 eight-stranded beta sheet with two helices [44-48]. The platform domain is subdivided into a1

24 and a2 domains, with each domain containing four beta strands and an alpha helix. Unlike

$25 \mathrm{MHCl}$, the groove between the helices of the NKG2DL platform domain is closed and therefore

26 NKG2DLs do not bind peptides. 
Like host NKG2DLs, OMCP also adopts an MHCl-like platform domain [38]. However,

2 the platform domain of OMCP has been trimmed to have only a six-stranded beta sheet with

3 shorter flanking helices. In this paper, we term the helix of the a1 domain $\mathrm{H} 1$ and the

4 discontinuous helix of the $a 2$ domain is termed $\mathrm{H} 2 \mathrm{a}$ and $\mathrm{H} 2 \mathrm{~b}$. The $\mathrm{H} 2 \mathrm{a}$ and $\mathrm{H} 2 \mathrm{~b}$ helices of

$5 \mathrm{OMCP}$ are also rearranged to be flatter against the beta sheet and to be splayed apart from

6 each other. These differences in the OMCP structure were hypothesized to be important for the

7 high affinity binding of OMCP to NKG2D. However, OMCP was still expected to bind to NKG2D

8 in the same orientation as host NKG2DLs, i.e. with the alpha helices oriented diagonally within

9 the symmetric NKG2D binding groove.

10 Here we report the $2.0 \AA$-resolution structure of human NKG2D bound to OMCP of the

11 Brighton Red strain of cowpoxvirus. The structure reveals a significant reorientation of OMCP in

12 the NKG2D binding groove relative to host NKG2DLs. The interface of OMCP with NKG2D is

13 highly complementary, buries a significantly larger surface area than host NKG2DLs, and

14 remains continuous across the entire NKG2D binding groove. This novel binding adaptation

15 and high affinity allows OMCP to compete with the high local concentration of membrane-

16 associated host NKG2DLs. We further show that the mechanism of NKG2D antagonism

17 requires OMCP to be secreted, lest it lead to NKG2D signaling. Finally, we show that viruses

18 expressing an NKG2D-binding deficient OMCP mutant are equivalently attenuated to viruses

19 that do not express OMCP using mouse models of cowpox infection. Thus demonstrating that

20 while FCRL5 plays no role in cowpox pathogenesis, OMCP is critical in attenuating NKG2D-

21 mediated immunity.

\section{Results}

\section{CPXV lacking OMCP is significantly attenuated in vivo.}

25 While OMCP has been shown to bind to NKG2D and compete with NKG2D ligands in vitro, the 26 effect of OMCP on CPXV virulence in vivo has not been determined. We generated an OMCP- 
1 deficient $(\triangle \mathrm{V} 018) \mathrm{CPXV}$ using a transient dominant selection strategy. Multi-step growth curves

2 of the WT CPXV, OMCP-deficient CPXV, and a revertant CPXV demonstrated nearly identical

3 replication growth kinetics (Fig. S1), indicating that OMCP is dispensable for viral growth or

4 replication in vitro.

$5 \quad$ Next we investigated the impact of OMCP during systemic CPXV infection (via the

6 intraperitoneal (i.p.) route) in WT B6 mice. Survival of WT mice infected with WT CPXV

7 demonstrated dose dependence with an LD50 value of $0.91 \times 10^{6} \mathrm{pfu} / \mathrm{mouse}$ (Fig. $1 \mathrm{~A}$ ).

8 Comparison of the survival of WT mice infected i.p. with OMCP-deficient CPXV (Fig. 1B)

9 revealed substantially greater survival in the mice infected with OMCP-deficient CPXV than with

10 WT CPX. Indeed, the LD50 value of $1.64 \times 10^{6} \mathrm{pfu} / \mathrm{mouse}$ for mice infected with OMCP-deficient

11 CPXV demonstrated that CPXV lacking OMCP is attenuated in vivo compared to WT CPXV.

12 Kaplan Meier survival curves of WT mice infected with the OMCP revertant CPXV correlate well

13 with the survival observed following infection with WT CPXV (Fig. 1C), demonstrating that the

14 decreased virulence observed during infection with OMCP-deficient CPXV reflects the absence

15 of OMCP. Together, these results establish for the first time that OMCP facilitates CPXV

16 virulence in vivo.

18 Structure determination of OMCP-NKG2D. We had previously solved the structure of OMCP

19 alone and shown that, similar to host NKG2DLs, OMCP adopts an MHCl-like platform domain

20 [38]. Despite the overall similarity of the domain structure of OMCP to host NKG2DLs, OMCP

21 had several notable deviations in the putative NKG2D-binding site that were hypothesized to be

22 important for the high affinity binding of OMCP to NKG2D. To further understand the unusually

23 high affinity of OMCP for NKG2D, we crystallized and solved the structure of OMCP bound to

24 human NKG2D.

25 Initial crystallization trials with OMCP and NKG2D yielded $\sim 30$ different crystallization

26 conditions. Subsequent data collection and molecular replacement of multiple low-resolution 
1 crystal forms all yielded similar partial solutions, with alternating sheets of OMCP-NKG2D

2 complexes separated by undefined density. In the original structure of OMCP alone, the beta

3 sheets packed to form a trimer with the alpha helices oriented away from the center [38]. An

4 identical OMCP trimer formed in the OMCP-NKG2D partial solutions, with NKG2D now bound to

5 the outward facing helices (data not shown). In an attempt to change the lattice packing, we

6 introduced mutations into the beta sheet of OMCP that were designed to break the trimeric

7 interface. These mutations were on the opposite face of OMCP from the NKG2D binding site to

8 avoid disrupting OMCP-NKG2D binding. A mutant form of OMCP (Y23D, F95D) crystallized

9 with NKG2D in a new space group and the crystals diffracted to $2.0 \AA$ (Table 1)(Figure $2 A)$.

10 The electron density map was continuous and unambiguous throughout all chains of the

11 structure, with the exception of Q108 in OMCP. This residue was situated in the center of the

12 largest loop of OMCP and unambiguous density for this residue was also absent from the

13 structure of OMCP alone [38]. The structure of OMCP bound to NKG2D showed no major

14 differences from our previous structure of OMCP alone, with an RMSD for all atoms of $0.8 \AA$.

15 Likewise, NKG2D was also similar to previous NKG2D structures with RMSDs ranging from 0.5-

$160.9 \AA$. The $\beta 3-\beta 4$ loop of NKG2D is the only region of either OMCP or NKG2D that displayed

17 above-average B factors. This loop is thought to be flexible and has had above average B

18 factors in all previous NKG2D structures [49]. Interestingly, the peptide bond between S193-

19 S194 in our NKG2D structure had a cis conformation not described in other NKG2D structures

20 (Figure S2).

22 The interface between OMCP and NKG2D. OMCP was hypothesized to bind to the same

23 surface of NKG2D used by host NKG2DLs because (i) OMCP competed with host NKG2DLs for

24 NKG2D and (ii) mutations within the NKG2DL-binding pocket of NKG2D altered OMCP binding

25 affinity [38]. OMCP does bind NKG2D using the same concave binding pocket as host

26 NKG2DLs (Figure 2A). OMCP binds primarily using the discontinuous helices of its a2 domain, 
$1 \mathrm{H} 2 \mathrm{a}$ and $\mathrm{H} 2 \mathrm{~b}$. The position of the $\mathrm{H} 2 \mathrm{a}$ and $\mathrm{H} 2 \mathrm{~b}$ helices is such that every surface exposed side

2 chain of both helices within the binding site directly contacts NKG2D (Figure 2B). Only two

3 contacts are found outside of $\mathrm{H} 2 \mathrm{a}$ and $\mathrm{H} 2 \mathrm{~b}$, Ile49 and Arg66. Both of these residues are within

4 the a1 domain but lie outside of the $\mathrm{H} 1$ helix.

5 Twelve OMCP residues contact eighteen NKG2D residues to form a mixture of bond

6 types (Table 2). Three residues in each NKG2D half-site are known as core binding residues

7 because they make contacts with all known host NKG2DLs. The core residues of NKG2D

8 subunit $A\left(N K G 2 D^{A}\right)$ (Tyr152, Tyr199, Met184) form two hydrogen bonds and make extensive

9 hydrophobic contacts with OMCP residues. The core residues of NKG2D ${ }^{A}$ contact four OMCP

10 residues and the most critical of these residues is Phe122. Phe122 makes multiple hydrophobic

11 contacts with all three NKG2DA core residues, including pi-stacking with Tyr152. Phe122 also

12 forms a backbone-to-sidechain hydrogen bond with Tyr152. Interestingly, OMCP is the first

13 NKG2D ligand not to utilize all six NKG2D core-binding residues, with only Met184 and Tyr152

14 of NKG2D subunit B (NKG2D $\left.{ }^{B}\right)$ contacting OMCP. NKG2D ${ }^{B}$ Met184 and Tyr152 each make a

15 single hydrogen bond and hydrophobic contacts with OMCP residues. Two OMCP residues,

16 Trp127 and Asp132, make contacts with both NKG2D protomers. OMCP Trp127 forms a

17 hydrogen bond to Lys150 of $\mathrm{NKG}_{2} \mathrm{D}^{\mathrm{A}}$ and makes several hydrophobic contacts with Leu148 of

18 NKG2D ${ }^{B}$, Lys150 and Ser151 of NKG2DA. OMCP Asp132 forms a hydrogen bond with Tyr152

19 of NKG2D $D^{B}$ and a salt bridge with Lys150 of NKG2D ${ }^{A}$ (Figure 3A).

20 Due to the high affinity of the OMCP-NKG2D interaction we harnessed a high throughput

21 in vitro selection approach to find NKG2D-binding null mutants (Table S1). The results of the

22 screen identified D132 as an important residue for disrupting NKG2D binding. We then

23 generated OMCP with the D132R mutation in an attempt to completely ablate NKG2D binding.

24 The D132R mutant protein was unable to bind to NKG2D-expressing cells, but retained binding

25 to FcRL5-expressing cells (Figure 3B). This mutation is likely to cause significant steric clashes, 
1 as well as disrupting both interactions made by Asp132 to NKG2D ${ }^{A}$ Lys150 and NKG2D ${ }^{B}$

2 Tyr152 (Figure 3A).

4 The role of OMCP receptors in CPXV infection. We generated a recombinant CPXV that

5 expressed the D132R mutant OMCP to isolate the effect of OMCP binding to NKG2D from

6 binding to FCRL5. A multi-step growth curve of (D132R) OMCP CPXV demonstrated identical

7 replication growth kinetics to WT CPXV (Fig. S1). Cowpox and its close relatives variola virus,

8 vaccinia virus, and monekeypox can be spread via contact and aerosol transmission [50];

9 therefore, we choose to study the role of OMCP during acute intranasal (i.n.) infection. Using

10 our series of WT OMCP expressing CPXV, OMCP-deficient CPXV ( $\triangle \mathrm{V} 018)$, and (D132R)

11 OMCP mutant expressing CPXV in combination with WT, NKG2D-deficient, and FcRL5-

12 deficient mice, we were able to delineate the impact of OMCP on NKG2D- and FcRL5-

13 expressing cells during CPXV infection in vivo.

14 Mice were infected i.n. with $2.5 \times 10^{4} \mathrm{pfu} /$ mouse of WT, OMCP-deficient, or D132R CPXV

15 virus. Infection with WT CPXV resulted in similar mortality in WT, NKG2D-deficient, and FcRL5-

16 deficient mice (Fig. 4 solid lines). However, the complete loss of OMCP (Fig. 4, dashed lines)

17 rendered CPXV severely attenuated in WT and FCRL5-deficient mice, while OMCP-deficient

18 CPXV infection in NKG2D-deficient mice remained similarly lethal as WT CPXV. These results

19 illustrated that under normal circumstances (i.e., WT CPXV infection in WT mice), OMCP is able

20 to effectively abrogate activation through the NKG2D receptor, rendering WT CPXV as lethal in

21 WT mice as it is in NKG2D-deficient mice. Mice infected with the (D132R) OMCP CPXV (Fig. 4,

22 dotted lines) phenocopied the mortality of mice infected with OMCP-deficient CPXV. The

23 survival observed in the FCRL5-deficient mice following infection with each of the strains of

24 CPXV closely mimicked that seen in WT mice (Figs. 4C vs 4A), indicating that there is no

25 significant role of the FcRL5 receptor on survival following this route of infection. The significant

26 attenuation of OMCP-deficient CPXV and the (D132R) OMCP CPXV infection in WT and 
1 FcRL5-deficient mice demonstrated the critical importance of NKG2D blockade during WT

2 CPXV infection, and strongly implicates OMCP blockade of NKG2D as the primary virulence

3 effect.

5 Glycosylated OMCP does not bind FcRL5. Compared to previous in vitro experiments with

6 bacterial-derived OMCP [37-39], OMCP produced in mammalian cells would be modified by N-

7 linked glycosylation. OMCP is glycosylated at N12, one of its two putative N-glycan sites, when

8 produced in mammalian cells (Fig S3A). The absence of a phenotype for FcRL5 in mice led us

9 to confirm whether mammalian-derived, glycosylated OMCP binds to FcRL5-expressing cells.

10 To test whether glycosylation would affect OMCP receptor binding, we compared binding of

11 bacterially-expressed or mammalian-expressed OMCP to $\mathrm{Ba} / \mathrm{f} 3$ cells expressing NKG2D or

12 FcRL5 (Fig. 5A). Regardless of source, OMCP bound to NKG2D-expressing cells. In contrast

13 to bacterially-expressed OMCP, mammalian-expressed OMCP did not bind to FcRL5-

14 expressing cells. To confirm whether the difference in FcRL5 binding was due to glycosylation,

15 mammalian-expressed OMCP was treated with EndoF to remove the $\mathrm{N}$-linked glycan. The

16 deglycosylated protein gained the ability to interact with FcRL5. Next we tested the binding of

17 mammalian-expressed OMCP to primary human PBMCs (Fig 5B). As a positive control for

18 NKG2D binding, we included the human NKG2DL ULBP3. WT OMCP and ULBP3 stained both

19 NK and a subset of T cells, but not B cells, consistent with NKG2D expression on these cells. In

20 contrast, (D132R) OMCP failed to significantly stain NK and T cells, supporting that WT OMCP

21 cell staining is due to binding NKG2D. Together the in vivo virulence (Fig 4) and cell binding

22 experiments (Fig 5) demonstrate that mammalian-derived OMCP functions only as a high

23 affinity NKG2D antagonist and is not a bona fide FcRL5 ligand. Importantly, OMCP blockade of

24 NKG2D plays a significant role in pathogenesis in mice, and potentially an even larger role with

25 higher affinity NKG2D orthologs, like human NKG2D. 
1 Structural basis for species-specific affinity. Previously, the 14-fold higher affinity of OMCP

2 for human vs murine NKG2D was mapped to three amino acid substitutions in the $\beta 5$ '- $\beta 5$ loop of

3 NKG2D, abbreviated L2 [38]. In addition to the substitutions themselves (I182V, M184I and

4 Q185P), the position of the loop between NKG2D orthologs differs. L2 in human NKG2D is bent

5 towards the center of the concave binding cavity compared to L2 of murine NKG2D.

6 Superimposition of murine NKG2D onto the human NKG2D-OMCP structure reveals that the

7 contacts between OMCP and Met184 (mNKG2D residue I200) in NKG2D ${ }^{B}$ and between Met184

8 (I200) and Glu185 (P201) in NKG2DA would be altered due to the different position of the

9 murine $\beta 5$ '- $\beta 5$ loop (Figure $6 \mathrm{~A}-\mathrm{B}$ ). This alteration would disrupt contacts with three residues in

10 OMCP H2a, three residues in $\mathrm{H} 2 \mathrm{~b}$ and Arg66 within the a1 domain. Of the contact residues of

11 L2, Met184 makes the most significant contacts in both NKG2Ds (Table 2)(Figure 6C).

12 Critically, of the 58 NKG2D sequences available in GenBank, 54 conserve the Met184 and

13 Glu185 found in the high affinity human NKG2D (Figure 6D).

14 Eighteen OMCP variants have been described between different CPXV and MPXV

15 strains [51]. In this study, we have crystallized OMCP from the Brighton Red strain of CPXV

16 which has $>60 \%$ sequence identity with the highly conserved sequence of the other 17 OMCP

17 variants, collectively termed $\mathrm{OMCP}_{\mathrm{mpx}}$. Of the $12 \mathrm{OMCP}$ contact residues observed, 9 are

18 identical to $\mathrm{OMCP}_{\mathrm{mpx}}$. Of the remaining contacts, all three are conservative hydrophobic

19 substitutions (I49L, T118I and M135I) (Figure 7). OMCP $_{m p x}$ binds to NKG2D and the

20 substitutions in the NKG2D contact residues are unlikely to grossly affect the affinity of

$21 \mathrm{OMCP}_{\mathrm{mpx}}$ for NKG2D [37].

23 A novel NKG2D-binding adaptation. Host NKG2DLs have low sequence identity but overall

24 similar structures, with $\mathrm{MHCl}$-like platform domains binding diagonally across the symmetric

25 binding groove created by the NKG2D homodimer [13, 42, 52]. Host ligands contact one

26 NKG2D half site with $\mathrm{H} 1$ and the S1-S2 loop, and contact the second NKG2D half site with H2b. 
1 Despite the similar $\mathrm{MHCl}$-like fold, OMCP binds the NKG2D binding groove in a novel

2 orientation, rotating $\sim 45^{\circ}$ relative to host NKG2DLs (Figure 7). Instead of using $\mathrm{H} 1$ and S1-S2

3 loop like host ligands, OMCP has replaced these contacts with $\mathrm{H} 2 \mathrm{a}$. This rotation leads to the

4 helices of OMCP being perpendicular to the NKG2D binding groove, instead of lying diagonally

5 across it.

6 Two unique rearrangements of $\mathrm{H} 2 \mathrm{a}$ and $\mathrm{H} 2 \mathrm{~b}$ make the OMCP orientation possible. The

$7 \quad$ a2 helices of OMCP and host NKG2DLs are discontinuous, with the two shorter helices hinged

8 relative to each other. For host ligands, the angle between $\mathrm{H} 2 \mathrm{a}$ and $\mathrm{H} 2 \mathrm{~b}$ is $\sim 90^{\circ}$, positioning

$9 \mathrm{H} 2 \mathrm{a}$ away from the NKG2D interface. In contrast, OMCP has increased the hinge angle

10 between the helices by $\sim 20^{\circ}$, leading to a $\alpha 2$ helix that is flatter relative to the beta sheet of

11 OMCP. The flattening of the $\mathrm{a} 2$ helix allows $\mathrm{H} 2 \mathrm{a}$ and $\mathrm{H} 2 \mathrm{~b}$ to closely complement the concave

12 binding groove of the NKG2D homodimer (Figure 2B). The tight fit of the $\alpha 2$ helix for NKG2D is

13 reflected in the high shape complementarity $(0.77)$ and buried surface area $\left(2,612 \AA^{2}\right)$. In

14 contrast, host NKG2DLs have shape complementarity ranging from 0.63-0.72 and buried

15 surface areas ranging from $1,700-2,180 \AA^{2}[44,45,47]$.

16 The second unique feature of the $a 2$ helix is the separation of $\mathrm{H} 2 \mathrm{a}$ and $\mathrm{H} 2 \mathrm{~b}$ relative to

17 each other. This region also contains a translation that completely separates $\mathrm{H} 2 \mathrm{a}$ and $\mathrm{H} 2 \mathrm{~b}$ into

18 two distinct helices. This translation is critical for NKG2D binding because it allows each helix to

19 be directly centered on the core binding sites of each NKG2D monomer (Figure 7). This creates

20 a symmetric binding site on OMCP that recognizes the symmetric binding groove created by the

21 NKG2D dimer. The symmetry between OMCP and NKG2D binding is in stark contrast to the

22 canonical binding of an asymmetric host ligand to the symmetric NKG2D binding groove [52].

23 However, one element of asymmetry remains in the OMCP-NKG2D interaction because each

24 NKG2D half-site recognizes an OMCP helix in a different $\mathrm{N}$ - to C-terminal orientation,

25 demonstrating again the flexibility of NKG2Ds rigid adaptation recognition $[42,53]$. 
The contact sites between NKG2D and host NKG2DLs are made up of two patches

2 centered on the core binding sites of NKG2D and H1/S1-S2 loop and H2b of NKG2DLs [42]. As

3 a result, the interface of NKG2D with NKG2DLs is discontinuous, particularly in the center of the

4 NKG2D binding groove (Figure 7). Due to the unique orientation of OMCP, H2a and H2b make

5 continuous contacts along the entire NKG2D binding groove (Figure 7). The sidechains of

6 OMCP Lys126, Trp127, Glu131 and Asp132 make contacts with residues in the center of the

$7 \quad$ NKG2D binding groove and bridge the core binding sites on each NKG2D monomer (Figure

8 2B). In particular, OMCP Trp127 is directed towards the center of the NKG2D dimer and makes

9 hydrophobic contacts with residues on both NKG2D monomers, effectively closing any gaps in

10 the binding interface.

12 Signaling of NKG2D upon ligand engagement. CPXV and MPXV-infected cells secrete

13 OMCP, which can act as an NKG2D-antagonist and block in vitro NKG2D-mediated NK cell

14 killing of target cells [37]. This immune evasion strategy is reminiscent of cancer induced-

15 NKG2DL shedding. Some cancer cells proteolytically cleave NKG2DLs from the cell surface

16 using matrix metalloproteinases (MMPs), simultaneously preventing NKG2D-bearing

17 lymphocytes from targeting the cancer cell, as well as creating soluble NKG2DLs to inhibit

18 NKG2D in trans. Cell-associated NKG2DLs trigger NKG2D effector functions (Figure 8A), while

19 cancer-induced, soluble NKG2DLs block NKG2D function (Figure 8B). Like shed NKG2DLs,

20 OMCP is soluble and blocks NKG2D function in trans [37] (Figure 8C). Unlike host NKG2DLs,

21 OMCP binds NKG2D with a novel orientation. We therefore asked whether OMCP could serve

22 as a NKG2D agonist in the context of the cell membrane, analogously to host NKG2D ligands.

23 Since OMCP is a secreted protein, an artificially cell-associated OMCP was constructed by

24 using a heterologous GPI anchor from Thy1.1 [37] (Figure 5D). To measure NKG2D-mediated

25 cell killing, we stably transduced Ba/F3 cells with retroviral vectors expressing either the OMCP-

26 Thy1.1 construct or host NKG2DLs. OMCP-Thy1.1-expressing target cells were killed 
1 equivalently to host NKG2DL-transduced target cells, indicating that despite its altered binding

2 orientation, cell-associated OMCP was able to activate NKG2D signaling (Figure 8E). Thus,

3 OMCP must be secreted lest it active NKG2D-effector functions itself, despite potential loss of

4 efficacy due to diffusion.

5

6 Discussion

21 NKG2D, cowpox virus was significantly attenuated. Cowpox virus inhibits the cell surface

22 expression of $\mathrm{MHCl}$ to avoid recognition by effector $\mathrm{T}$ cells[30, 31]. The loss of $\mathrm{MHCl}$

23 expression on the cell surface induces "missing self" and enhanced recognition by NK cells. In

24 the absence of OMCP antagonism of the activating NK cell receptor NKG2D, infected cells

25 become more susceptible to NK cell-mediated killing. 
While many viruses have adopted a general mechanism of NKG2D-sabotage by trying

2 to retain multiple host-encoded NKG2D ligands within the infected cell, CPXV and MPXV take

3 the very different approach of targeting NKG2D directly. Since NKG2D is monomorphic, this

4 mechanism has the significant advantage of requiring a single protein to prevent NKG2D

5 recognition of the infected cell. The large number of sequence-divergent host NKG2DLs and

6 their associated polymorphisms are thought to be driven by selection from pathogen-encoded

7 NKG2DL antagonists [14]. Likewise, viral NKG2L antagonists are under selective pressure from

8 the diverse host NKG2DLs in a continual cycle of adaptation. Due to the need to recognize

9 multiple NKG2DLs, NKG2D has a limited mutational space to adapt. The limited ability of

10 NKG2D to mutate is yet another advantage of OMCP directly targeting NKG2D, instead of

11 NKG2DLs.

12 Similarly to OMCP, some cancer cells shed host NKG2DLs to create their own soluble

13 NKG2D antagonists. However, this strategy has the additional benefit of removing host

14 NKG2DL from the surface of cancer cells. In contrast, CPXV and MPXV lack a known

15 mechanism of blocking host NKG2DL surface expression. Secreted OMCP must then be able

16 to compete efficiently against the high local concentration of multiple host NKG2DLs on the

17 infected cell, as well as against diffusion away from the infected cell. One possible way to

18 increase OMCP's ability to compete with host ligands would be to increase the avidity of OMCP

19 by having multiple NKG2D-binding domains. However, a multimeric OMCP could crosslink

20 NKG2D and potentially trigger NKG2D-mediated killing. Therefore, secreted OMCP must be

21 monomeric to prevent aberrant NKG2D signaling. Thus to compensate for these deficiencies,

22 OMCP must have the highest possible affinity to effectively compete against cell-associated

23 host NKG2DLs [37, 38]. The half-life of ligand-receptor interactions correlate well with

24 physiological competitiveness [54]. OMCP binds human and murine NKG2D with half-lives of

25348 and 54 seconds, respectively, compared to half-lives of $1.5-18$ seconds for most NKG2DLs

$26[38,45,55]$. Indeed, the increased half-life for NKG2D allows OMCP to effectively antagonize 
1 NKG2D-mediated immunity in our murine infection models despite the lower affinity of the

2 murine NKG2D receptor for OMCP compared to human NKG2D receptor. CPXV infections in

3 primates or rodents that express the higher affinity NKG2D receptor would likely be protected

4 from NKG2D-mediated immunity by OMCP to a greater degree.

5 To understand the molecular basis for the long half-life of OMCP for NKG2D, we

6 previously determined the structure of OMCP alone, and here, we report the structure of OMCP

7 bound to NKG2D. The structure of OMCP alone was grossly similar to that of host NKG2D

8 ligands, containing an atypical $\mathrm{MHCl}$-like platform domain. Host NKG2D ligands bind with the

9 helices of their platform domains oriented diagonally within the symmetric binding groove of

10 NKG2D. Thus it was expected that OMCP was a viral mimic of host NKG2D ligands and would

11 interact with NKG2D analogously.

12 The structure of OMCP-NKG2D instead revealed a novel orientation for an NKG2D

13 ligand in the NKG2D binding groove. Alterations within the a2 domain helix allow OMCP to

14 arrange its helices perpendicularly within the binding groove. This reorientation places the $\mathrm{H} 2 \mathrm{a}$

15 and $\mathrm{H} 2 \mathrm{~b}$ helices directly in contact with the core binding sites of NKG2D and also forms the

16 largest and most continuous binding interface with NKG2D. Because the forces (hydrogen

17 bonds, van der Waals, hydrophobic interactions) that mediate protein-protein interactions are

18 individually weak, a large, continuous interface with high shape complementary allows for a

19 cumulatively strong interaction between proteins. This change in the binding orientation of

20 OMCP reveals how the $\mathrm{MHCl}$-like platform used by host ligands can be adapted by a pathogen

21 to enhance NKG2D binding.

22 Since host NKG2DLs and OMCP have a similar MHCl-like platform, it is reasonable to

23 wonder why no host ligand has evolved an analogous high-affinity interaction with NKG2D. One

24 likely reason is that the host immune response must be carefully calibrated to balance the need

25 for protection against the threat of autoimmunity. Since the expression of NKG2DLs on the cell

26 surface signals for effector functions, even a small amount of high affinity host ligand on the cell 
1 surface could trigger an immune response, and the resulting tissue damage could be

2 deleterious for the host. Indeed, NKG2D-expressing cells and/or aberrant expression of host

3 NKG2DLs have been implicated in diabetes, celiac disease and rheumatoid arthritis [56-59].

4 Viruses are not constrained by autoimmune selective pressures. Therefore, CPXV and MPXV

5 were free to evolve a viral NKG2DL with the highest possible affinity to maximize immune

6 evasion potential.

7 Interestingly, OMCP triggers NKG2D signaling when attached to a target cell membrane,

8 despite the novel orientation of OMCP relative to host NKG2DLs. The interaction of host

9 NKG2DLs with the dimeric NKG2D bears broad structural similarity to the interaction between

10 MHC molecules with their cognate T cell receptors (TCRs). In both cases, the NKG2DL/MHC

11 lies diagonally across the surface created by the dimeric NKG2D/TCR. However, there are

12 several examples of MHC-TCR complexes that, like OMCP-NKG2D, interact with

13 unconventional orientations [60-64]. Several of these complexes involved autoimmune MHC-

14 TCR complexes that were tilted or rotated outside of the normal range for MHC-TCR complexes

$15[60,64]$. While these receptors could induce TCR signaling at high MHC concentrations, they

16 failed to assemble characteristic immunological synapses [65]. A striking example of

17 unconventional binding was found when an in vitro peptide library-MHC-TCR (H2-L $\left.{ }^{d}-42 F 3\right)$

18 screen produced a $\mathrm{p} 3 \mathrm{~A} 1-\mathrm{H} 2-\mathrm{L}^{\mathrm{d}}-42 \mathrm{~F} 3$ complex with an interface rotated $\sim 40^{\circ}$ relative to other

$19 \mathrm{H} 2-\mathrm{L}^{\mathrm{d}}-42 \mathrm{~F} 3$ complexes. This rotation places the TCR nearly parallel with the MHC peptide-

20 binding groove and shifted the interface center almost entirely on one of the MHC a helices - an

21 orientation strikingly similar to the interface of OMCP-NKG2D [64]. Interestingly, the p3A1-H2-

$22 \mathrm{~L}^{\mathrm{d}}-42 \mathrm{F3}$ complex failed to induce TCR signaling [64]. Thus, unlike OMCP/NKG2D, the

23 orientation of $\mathrm{MHC}$ relative to TCR is an important factor for signaling.

24 OMCP-NKG2D and $\mathrm{p} 3 \mathrm{~A} 1-\mathrm{H} 2-\mathrm{L}^{\mathrm{d}}-42 \mathrm{~F} 3$ have opposite signaling outcomes, despite having

25 very similar orientations. TCR signaling requires co-receptor binding to either the $\alpha 2 / \beta 2$ or $\alpha 3$

26 domains of $\mathrm{MHCll}$ or $\mathrm{MHCl}$, respectively. The failure of $\mathrm{p} 3 \mathrm{~A} 1-\mathrm{H} 2-\mathrm{L}^{\mathrm{d}}-42 \mathrm{~F} 3$ to signal, and of other 
1 unconventional MHC-TCR complexes to form true immunological synapses, is potentially due to

2 the inability of co-receptors to form correct quaternary structures for signaling [63, 64, 66].

3 Signaling by NKG2D is not known to require co-receptor stimulation and the majority of

$4 \quad$ NKG2DLs lack the co-receptor binding $\alpha 2 / \beta 2$ or $\alpha 3$ domains of true MHC molecules. This

5 difference in co-receptor dependency likely explains why OMCP (when attached via GPI

6 anchor) is still competent to stimulate NKG2D-signaling compared to MHC-TCR complexes with

7 unconventional binding orientations. Further, it suggests that clustering of NKG2D on the cell

8 surface is the major determinant of NKG2D-mediated activation.

\section{Materials and Methods}

\section{Cell lines and mice.}

12 The generation of Ba/F3 transductants expressing NKG2D, FcRL5, RAE1 $\delta$, MULT1, and

13 OMCP-Thy1.1 was previously described [37, 67]. C57BL/6 (B6) mice were obtained from the

14 National Cancer Institute (Charles River, MA). NKG2D-deficient mice on a B6 background were

15 a kind gift from Bojan Polic (University of Rijeka, Croatia) [68], and FcRL5-deficient mice on a

16 B6 background were obtained from Riccardo Dalla Favera (Columbia University). Mice were

17 maintained under specific pathogen-free conditions and used between 8 and 12 weeks of age.

18 Female mice utilized in survival studies were observed daily after infection for 28 days and 19 moribund mice were euthanized per institutional guidelines.

\section{Ethics Statement.}

22 All experiments were conducted in accordance with institutional guidelines for animal care and

23 use based on the Guide for the Care and Use of Laboratory Animals of the National Institutes of

24 Health. The protocol was approved by the Animal Studies Committee at Washington University

25 (\#20110104). Human PBMC were collected under IRB approved protocol \#201110275 at 
1 Washington University in St Louis. Informed consent was obtained from all volunteers donating

2 blood.

$4 \quad$ CPXV and infection of mice.

5 Brighton Red strain CPXV was obtained from the ATCC and propagated in BS-C-1 cells. Virus

6 was purified from infected BS-C-1 cell lysates by centrifugation through a $36 \%$ sucrose gradient.

7 The titer of the viral stock was determined using a standard plaque assay on BS-C-1 cells [69,

8 70]. Intraperitoneal (i.p.) infections were done at a dose of $2 \times 10^{6}$ pfu CPXV/mouse unless

9 otherwise indicated. For intranasal infections, mice were first anesthetized i.p. with

10 ketamine/xylazine short acting sedative. Mice were infected with the appropriate innoculum of

11 virus in a $50 \mu \mathrm{L}$ volume intranasally. All i.n. infections were done at a dose of $2.5 \times 10^{4}$ pfu

$12 \mathrm{CPXV} / \mathrm{mouse}$ unless otherwise indicated.

\section{Generation of recombinant cowpox viruses.}

15 Recombinant virus lacking expression of OMCP $(\Delta \mathrm{V} 018)$ and its revertant were produced by 16 transient dominant selection [71, 72]. A PCR product encoding the VACV p7.5 5' UTR and 17 promoter was amplified and spliced to another PCR product encoding the E. coli gpt sequence.

18 The final product was cloned into plasmid pUC19 to create pUC19 p7.5 gpt. OMCP was then 19 amplified in two fragments in order to insert two tandem early termination codons. This product 20 was cloned into pUC19 $7.5 \mathrm{gpt}$ to create pUC19 p7.5 gpt OMCPSTOP. The revertant plasmid 21 pUC19 p7.5 gpt OMCP was generated by excising the OMCPSTOP sequence and replacing it

22 with wild-type OMCP. OMCP D132R mutant CPXV was generated in a similar manner with

23 primers to insert a point mutation at D132. The mutated D132R construct was also spliced to $E$.

24 coli gpt and cloned for transient dominant selection. 
1 Confluent CV-1 cells were then infected with CPXV (for CPXV $\triangle$ V018 or D132R generation) or

$2 \mathrm{CPXV} \Delta \mathrm{V} 018$ (for revertant generation) at an $\mathrm{MOI}$ of 0.5 . Two hours post-infection, the cells

3 were transfected with pUC19 p7.5 gpt OMCPSTOP for CPXV $\triangle$ V018, pUC19 p7.5 gpt OMCP-

4 D132R for D132R generation, or pUC19 p7.5 gpt OMCP for revertant generation using

5 Lipofectamine2000. The infected/transfected cells were lysed after 48 hours, and gpt+ viruses

6 were selected by infecting confluent B-SC-1 cells with the transfected virus stock in gpt

7 selection medium (DMEM, 2\% FCS, $25 \mu \mathrm{g} / \mathrm{mL}$ mycophenolic acid, $250 \mu \mathrm{g} / \mathrm{mL}$ xanthine, and 15

$8 \mu \mathrm{g} / \mathrm{mL}$ hypoxanthine). Gpt+ viral plaques underwent two further rounds of selection in gpt

9 selection media and two subsequent rounds of purification in non-selective media. Finally,

10 plaques were tested for their ability to grow in both selective and non-selective media. Plaques

11 that grew only in non-selective media (indicating loss of the gpt marker) were picked and

12 underwent a total of five plaque purifications. Virus stocks were subsequently propagated in B-

13 SC-1 cells and titered following standard protocols using B-SC-1 cells [70].

15 Identification of NKG2D-binding null mutant D132R. A high throughput in vitro selection

16 approach based on combinatorial cell surface display was utilized to identify NKG2D-binding

17 null mutants. The sequence of OMCP was globally mutagenized using error-prone PCR, and

18 the mutated amplicons were spliced to a signal-less Thy1.1 cDNA via overlap extension PCR.

19 This library of mutated OMCPs fused to unmutated Thy1.1 was cloned into the pMXs-IRES-

20 EGFP retroviral transfer vector (kind gift of Toshio Kitamura, University of Tokyo) to generate a

21 molecular library for transduction into $\mathrm{Ba} / \mathrm{F} 3$ cells. The transductants were then sorted for green

22 fluorescence and anti-Thy1.1 expression to yield a cellular library whose members all had

23 surface expression of OMCP, filtering out mutations giving frameshifts, premature stop codons,

24 and folding-incompetent OMCP. This OMCP library was sorted for NKG2D binding using

25 NKG2D-tetramers. Sorted cells were cloned by limiting dilution and analyzed. The retroviral

26 cassettes of cells lacking or having reduced NKG2D-binding activity were amplified and 
1 sequenced. Utilizing this approach, we identified Asp132 as a critical residue for NKG2D

2 binding.

4 Protein expression and purification. $\mathrm{OMCP}_{\mathrm{BR}}$ and human NKG2D expression constructs

5 were previously described [38]. The (D132R) $\mathrm{OMCP}_{\mathrm{BR}}$ protein was prepared identically to WT

$6 \mathrm{OMCP}_{\mathrm{BR}}$. (23D/95D) OMCP-NKG2D complex was reconstituted by oxidative co-refolding from

7 purified inclusion bodies, as described previously [38]. Refolded protein was slowly diluted 10-

8 fold with water and captured on a $5 \mathrm{ml}$ HiTrap Q HP column (GE Healthcare) using a Profinia

9 instrument (Bio-Rad). The captured protein was washed with $50 \mathrm{mM}$ Tris, $\mathrm{pH} 8.5,20 \mathrm{mM} \mathrm{NaCl}$

10 and bulk eluted with $50 \mathrm{mM}$ Tris, $\mathrm{pH} 8.5,250 \mathrm{mM} \mathrm{NaCl}$. The eluted protein was then

11 concentrated and further purified by gel filtration chromatography on a Superdex S75 column

12 (16/60; Amersham Biosciences). Fractions containing mono-dispersed OMCP-NKG2D complex

$13(\sim 50 \mathrm{KDa})$ were pooled and buffer exchanged into $25 \mathrm{mM}$ Ammonium acetate $\mathrm{pH} 7.4$.

14 Mammalian-derived proteins were expressed by transient transfection of HEK293F cells

15 (Life Technologies) using PEI. The culture medium was collected 3 days and 6 days after

16 transfection, and then purified by standard Ni-NTA chromatography in accordance with the

17 manufacturer's protocol (Gold Biotechnology) and were subsequently buffer exchanged into

18 phosphate-buffered saline (PBS). Pentamerized proteins were made by fusing the target protein

19 with a C-terminal cartilage oligomeric matrix protein (COMP) domain [73].

21 Crystallization, data collection and processing. Native protein crystals were grown by

22 hanging drop vapor diffusion at $20^{\circ} \mathrm{C}$ by streak seeding into a well solution containing $15 \%$ PEG

$233350,0.2 \mathrm{M} \mathrm{MgCl}_{2}, 0.1 \mathrm{M}$ Bis-Tris $\mathrm{pH}$ 6.75. Crystals were cryoprotected with well solution

24 containing $15 \%$ glycerol before flash freezing directly in a liquid nitrogen bath. Diffraction data

25 were collected at the Advanced Light Source synchrotron (beamline 4.2.2). Native (23D/95D)

26 OMCP-hNKG2D crystal diffraction data were collected at $100 \mathrm{~K}$ and at a wavelength of 1.00004 
$1 \AA$ A. Additional diffraction data statistics are summarized in Table 1. Data processing with

2 HKL2000 [74] showed the crystals belonged to the primitive monoclinic space group P2 ${ }_{1}$ (space

3 group \#4). The asymmetric unit of the crystal contained two copies of the (23D/95D) OMCP.

4 hNKG2D complex.

5

6 Model building and refinement. The structures of human NKG2D (1MPU)[49] and OMCP

7 (4FFE)[38] were used as search models for molecular replacement through Phenix [75].

8 Reiterative refinement and manual rebuilding were performed using Phenix and Coot [76],

9 respectively. Both $2 \mathrm{Fo}-\mathrm{Fc}$ and Fo-Fc maps were used for manual building and to place solvent

10 molecules. The final model yielded an $R_{\text {work }}$ of $16.6 \%$ and $R_{\text {free }}$ of $21.4 \%$, with $4 \%$ of all

11 reflections set aside for free $\mathrm{R}$ factor cross-validation. Progress in refinement was also

12 measured using the MOLPROBITY webserver [77]. The final Ramachandran statistics for the

13 model were $98 \%$ favored and $0 \%$ outliers. Additional refinement statistics are summarized in

14 Table 1. Images of structures were produced using the program PyMol [78].

16 Structure analysis. Analysis of the contact residues, buried surface area and shape

17 complementarity of the OMCP-NKG2D interface were carried out using the programs Ligplot+

18 [79], PISA [80] and SC [81]. Structural programs as compiled by the SBGrid consortium [82].

19 Analysis of NKG2D conservation was performed using the ConSurf server [83-86]. GenBank

20 numbers for species used in Consurf analysis are: Humans (30749494), Borean orangutan

21 (21902299), Chimpanzee (57113989), Gibbon (332232684), Macaque (355785888), Green

22 Monkey (635063485), Common marmoset (380848799), Mouse (148667521), Brown rat

23 (149049263), Guinea Pig (348569092), Ground squirrel (532114387), Deer mouse

24 (589967905), Naked mole rat (512868733), Prairie vole (532053033), European Shrew

25 (505834608), Star-nosed mole (507978716), Chinese hamster (537136230), and Cat

26 (410963826). 


\section{Atomic coordinates}

3 The atomic coordinates (accession code 4PDC) have been deposited in the Protein Data Bank,

4 Research Collaboratory for Structural Bioinformatics (Rutgers University, New Brunswick, NJ)

6 In vitro NK cell killing assays. Splenocytes from C57BL/6 mice were preactivated with 200

$7 \mathrm{U} / \mathrm{ml} \mathrm{IL}-2$ for 24 hours and used as cytotoxic effectors against stably transduced Ba/F3 cell lines

8 in standard killing assays. Target cells were carboxyfluorescein succinimidyl ester (CFSE)

9 labeled and co-incubated with activated splenocytes at $37^{\circ} \mathrm{C}, 5 \% \mathrm{CO} 2$ for 4 hours at

10 effector:target ratios of 10:1, 20:1, and 40:1. Killing percentage was determined by incorporation

11 of the dead cell exclusion dye 7-amino-actinomycin D (7AAD) in the CFSE+ target population as

12 assessed by flow cytometry. Percent specific lysis was calculated using the formula

13 [(experimental dead \% - background dead \%) / (maximum release dead \% - background dead

$14 \%)] \times 100$. Single cell suspensions of splenocytes used in killing assays were generated using

15 standard protocols[87].

17 Antibodies, and Flow cytometry.

18 Recombinant OMCP, D132R OMCP, and West Nile Virus glycoprotein domain III (DIII) were

19 produced and biotinylated as previously reported $[37,88]$. APC labeled tetramers were made

20 by incubating biotinylated OMCP protein with APC-streptavidin in a 4:1 molar ratio for 10 min at

21 room temperature. APC eFlour 780 anti-CD3 (145-2C11) and eFlour 450 anti-CD19 (1D3) were

22 purchased from eBioscience (San Diego, CA). FITC CD19 (1D3) and PE anti-NK1.1 (PK136

23 were from BD Biosciences (San Jose, CA). FITC anti-CD5 (53-7.3) was from Biolegend (San

24 Diego, CA). Antibodies and staining of human PBMCs were performed as previously reported

25 [39]. Single cell suspensions of splenocytes and isolation of peritoneal cells and Ficoll

26 purification of human PBMCs were performed using standard protocols [87, 89]. To block 
1 nonspecific binding of antibodies to FcRs, murine cells were incubated in 2.4G2 (anti-FcyRII/III)

2 supernatants (hybridoma from ATCC) prior to staining with labeled Abs. Data was collected on a

3 FACScan flow cytometer (BD Pharmingen) with DxP multicolor upgrade (Cytek Development,

4 Fremont, CA) and FlowJo CE software (TreeStar, Ashland, OR) or FACSCalibur flow cytometer

5 (BD Biosciences) with CellQuest collection software (BD Biosciences). Data analysis was

6 performed using FlowJo software (TreeStar).

8 Plaque assay.

9 Tissues harvested from mice were weighed and collected in tubes containing $1 \mathrm{~mL}$ of DMEM

10 and stored at $-80^{\circ} \mathrm{C}$ until processing. Frozen organs were homogenized using glass dounce

11 homogenizers and collected in $1 \mathrm{~mL}$ of DMEM. The tissue homogenate was serially diluted in

12 D2.5 media (DMEM, 2.5\% FBS, 1\% L-glutamine, 1\% penicillin-streptomycin, 1\% non-essential

13 amino acids) and used in standard plaque assays on BS-C-1 cells [69]. Each organ was titered

14 on $5 \times 10^{5}$ BS-C- 1 cells plated in wells of 6 well plates in duplicate. Infected cell cultures were

15 maintained in $\mathrm{D} 2.5$ media at $37^{\circ} \mathrm{C}, 5 \% \mathrm{CO}_{2}$ for 48 hours. Cells were stained at 48 hours post

16 infection using a crystal violet solution and plaques were counted. Viral titers were calculated

17 from a minimum of 3 dilutions done in duplicate.

19 Statistical analysis.

20 Data analysis was done with Microsoft Excel and GraphPad Prism (GraphPad Software, La

21 Jolla, CA). Unless otherwise noted, unpaired, two-tailed t tests were used to determine

22 statistically significant differences. Error bars in the figures represent SDs from the mean value.

23 The Log-rank (Mantel-Cox) test was used in the comparison of all Kaplan Meier survival curves.

\section{Acknowledgements}


1 E.L., X.W., C.N., and D.H.F. were supported in part by NIH/NIAID R01 AI019687, U19

2 Al109948 and NIAID contracts HHSN272200700058C \& HHSN272201200026C. M.M.S, T.L.G,

3 D.L, and A.R.F were supported in part by NIH/NIAID R01AI073552. A.S.K. supported by NIH

$4 \quad$ PO1 Al116501. We thank Helen M. Lazear for help with illustrations 


\section{References}

2 1. Hansen TH, Bouvier M. MHC class I antigen presentation: learning from viral evasion 3 strategies. Nature reviews Immunology. 2009;9(7):503-13. Epub 2009/06/06. doi: 4 10.1038/nri2575. PubMed PMID: 19498380.

52 2. Griffin BD, Verweij MC, Wiertz EJ. Herpesviruses and immunity: the art of evasion. Vet 6 Microbiol. 2010;143(1):89-100. Epub 2010/03/23. doi: 10.1016/j.vetmic.2010.02.017. PubMed 7 PMID: 20303681.

8 3. Karre K, Ljunggren HG, Piontek G, Kiessling R. Selective rejection of H-2-deficient 9 lymphoma variants suggests alternative immune defence strategy. Nature. 1986;319(6055):675killer cells. Nature immunology. 2002;3(11):1006-12. Epub 2002/10/31. doi: 10.1038/ni11021006. PubMed PMID: 12407408.

5. Lisnic VJ, Krmpotic A, Jonjic S. Modulation of natural killer cell activity by viruses. Current opinion in microbiology. 2010;13(4):530-9. Epub 2010/06/19. doi: 10.1016/j.mib.2010.05.011. PubMed PMID: 20558100; PubMed Central PMCID: PMC2920364.

6. Finton KA, Strong RK. Structural insights into activation of antiviral NK cell responses. Immunological reviews. 2012;250(1):239-57. Epub 2012/10/11. doi: 10.1111/j.1600065X.2012.01168.x. PubMed PMID: 23046134; PubMed Central PMCID: PMC3471384.

7. Li Y, Mariuzza RA. Structural Basis for Recognition of Cellular and Viral Ligands by NK Cell Receptors. Front Immunol. 2014;5:123. Epub 2014/04/12. doi: 10.3389/fimmu.2014.00123. PubMed PMID: 24723923; PubMed Central PMCID: PMC3972465.

8. Raulet DH. Roles of the NKG2D immunoreceptor and its ligands. Nature reviews Immunology. 2003;3(10):781-90. Epub 2003/10/03. doi: 10.1038/nri1199. PubMed PMID: 14523385.

9. Draghi M, Pashine A, Sanjanwala B, Gendzekhadze K, Cantoni C, Cosman D, et al. NKp46 and NKG2D recognition of infected dendritic cells is necessary for NK cell activation in the human response to influenza infection. J Immunol. 2007;178(5):2688-98. Epub 2007/02/22. PubMed PMID: 17312110.

10. Pappworth IY, Wang EC, Rowe M. The switch from latent to productive infection in epstein-barr virus-infected $B$ cells is associated with sensitization to NK cell killing. Journal of virology. 2007;81(2):474-82. Epub 2006/11/03. doi: 10.1128/JVI.01777-06. PubMed PMID: $17079298 ;$ PubMed Central PMCID: PMC1797427.

11. Welte SA, Sinzger C, Lutz SZ, Singh-Jasuja H, Sampaio KL, Eknigk U, et al. Selective intracellular retention of virally induced NKG2D ligands by the human cytomegalovirus UL16 glycoprotein. European journal of immunology. 2003;33(1):194-203. Epub 2003/02/21. doi: 10.1002/immu.200390022. PubMed PMID: 12594848.

12. Ward J, Bonaparte M, Sacks J, Guterman J, Fogli M, Mavilio D, et al. HIV modulates the expression of ligands important in triggering natural killer cell cytotoxic responses on infected primary T-cell blasts. Blood. 2007;110(4):1207-14. Epub 2007/05/22. doi: 10.1182/blood-200606-028175. PubMed PMID: 17513617; PubMed Central PMCID: PMC1939902.

13. Obeidy $P$, Sharland AF. NKG2D and its ligands. Int $J$ Biochem Cell Biol. 2009;41(12):2364-7. Epub 2009/07/28. doi: 10.1016/j.biocel.2009.07.005. PubMed PMID: 19631280.

14. Eagle RA, Trowsdale J. Promiscuity and the single receptor: NKG2D. Nature reviews Immunology. 2007;7(9):737-44. Epub 2007/08/04. doi: 10.1038/nri2144. PubMed PMID: 17673918.

15. Lodoen M, Ogasawara K, Hamerman JA, Arase H, Houchins JP, Mocarski ES, et al. NKG2D-mediated natural killer cell protection against cytomegalovirus is impaired by viral gp40 modulation of retinoic acid early inducible 1 gene molecules. The Journal of experimental medicine. 2003;197(10):1245-53. Epub 2003/05/21. doi: 10.1084/jem.20021973. PubMed PMID: 12756263; PubMed Central PMCID: PMC2193789.

16. Lodoen MB, Abenes G, Umamoto S, Houchins JP, Liu F, Lanier LL. The cytomegalovirus m155 gene product subverts natural killer cell antiviral protection by disruption of H60-NKG2D interactions. The Journal of experimental medicine. 2004;200(8):1075-81. Epub 2004/10/13. doi:

56 10.1084/jem.20040583. PubMed PMID: 15477345; PubMed Central PMCID: PMC2211837. 
17. Krmpotic A, Hasan M, Loewendorf A, Saulig T, Halenius A, Lenac T, et al. NK cell activation through the NKG2D ligand MULT-1 is selectively prevented by the glycoprotein encoded by mouse cytomegalovirus gene m145. The Journal of experimental medicine. 2005;201(2):211-20. Epub 2005/01/12. doi: 10.1084/jem.20041617. PubMed PMID: 15642742; PubMed Central PMCID: PMC2212792.

18. Lenac T, Budt M, Arapovic J, Hasan M, Zimmermann A, Simic H, et al. The herpesviral Fc receptor fcr-1 down-regulates the NKG2D ligands MULT-1 and H60. The Journal of experimental medicine. 2006;203(8):1843-50. Epub 2006/07/13. doi: 10.1084/jem.20060514. PubMed PMID: 16831899; PubMed Central PMCID: PMC2118374.

19. Cosman D, Mullberg J, Sutherland CL, Chin W, Armitage R, Fanslow W, et al. ULBPs, novel MHC class I-related molecules, bind to CMV glycoprotein UL16 and stimulate NK cytotoxicity through the NKG2D receptor. Immunity. 2001;14(2):123-33. Epub 2001/03/10. PubMed PMID: 11239445.

20. Chalupny NJ, Rein-Weston A, Dosch S, Cosman D. Down-regulation of the NKG2D ligand MICA by the human cytomegalovirus glycoprotein UL142. Biochem Biophys Res Commun. 2006;346(1):175-81. Epub 2006/06/06. doi: 10.1016/j.bbrc.2006.05.092. PubMed PMID: 16750166 .

21. Thomas M, Boname JM, Field S, Nejentsev S, Salio M, Cerundolo V, et al. Downregulation of NKG2D and NKp80 ligands by Kaposi's sarcoma-associated herpesvirus K5 protects against NK cell cytotoxicity. Proceedings of the National Academy of Sciences of the United States of America. 2008;105(5):1656-61. Epub 2008/01/31. doi: 10.1073/pnas.0707883105. PubMed PMID: 18230726; PubMed Central PMCID: PMC2234200.

22. Cerboni C, Neri F, Casartelli N, Zingoni A, Cosman D, Rossi P, et al. Human immunodeficiency virus 1 Nef protein downmodulates the ligands of the activating receptor NKG2D and inhibits natural killer cell-mediated cytotoxicity. The Journal of general virology. 2007;88(Pt 1):242-50. Epub 2006/12/16. doi: 10.1099/vir.0.82125-0. PubMed PMID: 17170457. 23. Wen $\mathrm{C}, \mathrm{He} \mathrm{X}, \mathrm{Ma} \mathrm{H}$, Hou N, Wei C, Song $\mathrm{T}$, et al. Hepatitis $\mathrm{C}$ virus infection downregulates the ligands of the activating receptor NKG2D. Cellular \& molecular immunology. 2008;5(6):475-8. Epub 2009/01/03. doi: 10.1038/cmi.2008.60. PubMed PMID: 19118515.

24. Stern-Ginossar N, Elefant N, Zimmermann A, Wolf DG, Saleh N, Biton M, et al. Host immune system gene targeting by a viral miRNA. Science. 2007;317(5836):376-81. Epub 2007/07/21. doi: 10.1126/science.1140956. PubMed PMID: 17641203.

25. Nachmani D, Stern-Ginossar N, Sarid R, Mandelboim O. Diverse herpesvirus microRNAs target the stress-induced immune ligand MICB to escape recognition by natural killer cells. Cell host \& microbe. 2009;5(4):376-85. Epub 2009/04/22. doi: 10.1016/j.chom.2009.03.003. PubMed PMID: 19380116.

26. Bauman $Y$, Nachmani D, Vitenshtein A, Tsukerman P, Drayman N, Stern-Ginossar N, et al. An identical miRNA of the human JC and BK polyoma viruses targets the stress-induced ligand ULBP3 to escape immune elimination. Cell host \& microbe. 2011;9(2):93-102. Epub 2011/02/16. doi: 10.1016/j.chom.2011.01.008. PubMed PMID: 21320692.

27. Gainey MD, Rivenbark JG, Cho H, Yang L, Yokoyama WM. Viral MHC class I inhibition evades CD8+ T-cell effector responses in vivo but not CD8+ T-cell priming. Proceedings of the National Academy of Sciences of the United States of America. 2012;109(47):E3260-7. Epub 2012/11/01. doi: 10.1073/pnas.1217111109. PubMed PMID: 23112205; PubMed Central PMCID: PMC3511129.

28. Byun M, Verweij MC, Pickup DJ, Wiertz EJ, Hansen TH, Yokoyama WM. Two mechanistically distinct immune evasion proteins of cowpox virus combine to avoid antiviral CD8 $T$ cells. Cell host \& microbe. 2009;6(5):422-32. Epub 2009/11/18. doi: 10.1016/j.chom.2009.09.012. PubMed PMID: 19917497; PubMed Central PMCID: PMC2791900. 29. Byun M, Wang X, Pak M, Hansen TH, Yokoyama WM. Cowpox virus exploits the endoplasmic reticulum retention pathway to inhibit $\mathrm{MHC}$ class I transport to the cell surface. Cell host \& microbe. 2007;2(5):306-15. Epub 2007/11/17. doi: 10.1016/j.chom.2007.09.002. PubMed PMID: 18005752.

30. McCoy WHt, Wang X, Yokoyama WM, Hansen TH, Fremont DH. Cowpox virus employs a two-pronged strategy to outflank $\mathrm{MHCl}$ antigen presentation. Molecular immunology. 2013. Epub 2013/01/15. doi: 10.1016/j.molimm.2012.11.011. PubMed PMID: 23312338. 
31. McCoy WHt, Wang X, Yokoyama WM, Hansen TH, Fremont DH. Structural mechanism of ER retrieval of MHC class I by cowpox. PLoS biology. 2012;10(11):e1001432. Epub 2012/12/05. doi: 10.1371/journal.pbio.1001432. PubMed PMID: 23209377; PubMed Central PMCID: PMC3507924.

32. Alzhanova D, Edwards DM, Hammarlund E, Scholz IG, Horst D, Wagner MJ, et al. Cowpox virus inhibits the transporter associated with antigen processing to evade $T$ cell recognition. Cell host \& microbe. 2009;6(5):433-45. Epub 2009/11/18. doi: 10.1016/j.chom.2009.09.013. PubMed PMID: 19917498; PubMed Central PMCID: PMC2791678.

33. Dasgupta A, Hammarlund E, Slifka MK, Fruh K. Cowpox virus evades CTL recognition and inhibits the intracellular transport of MHC class I molecules. J Immunol. 2007;178(3):165461. Epub 2007/01/24. PubMed PMID: 17237415.

34. Luteijn RD, Hoelen H, Kruse E, van Leeuwen WF, Grootens J, Horst D, et al. Cowpox Virus Protein CPXV012 Eludes CTLs by Blocking ATP Binding to TAP. J Immunol. 2014;193(4):1578-89. Epub 2014/07/16. doi: 10.4049/jimmunol.1400964. PubMed PMID: 25024387.

35. Fang M, Lanier LL, Sigal LJ. A role for NKG2D in NK cell-mediated resistance to poxvirus disease. PLoS pathogens. 2008;4(2):e30. Epub 2008/02/13. doi: 10.1371/journal.ppat.0040030. PubMed PMID: 18266471; PubMed Central PMCID: PMC2233669.

36. Song H, Josleyn N, Janosko K, Skinner J, Reeves RK, Cohen M, et al. Monkeypox virus infection of rhesus macaques induces massive expansion of natural killer cells but suppresses natural killer cell functions. PloS one. 2013;8(10):e77804. Epub 2013/10/23. doi: 10.1371/journal.pone.0077804. PubMed PMID: 24147080; PubMed Central PMCID: PMC3798392.

37. Campbell JA, Trossman DS, Yokoyama WM, Carayannopoulos LN. Zoonotic orthopoxviruses encode a high-affinity antagonist of NKG2D. J Exp Med. 2007;204(6):1311-7. doi: 10.1084/jem.20062026. PubMed PMID: 17548517.

38. Lazear E, Peterson LW, Nelson CA, Fremont DH. Crystal structure of the cowpox virusencoded NKG2D ligand OMCP. Journal of virology. 2013;87(2):840-50. Epub 2012/11/02. doi: 10.1128/JVI.01948-12. PubMed PMID: 23115291; PubMed Central PMCID: PMC3554055.

39. Campbell JA, Davis RS, Lilly LM, Fremont DH, French AR, Carayannopoulos LN. Cutting edge: FcR-like 5 on innate $B$ cells is targeted by a poxvirus MHC class I-like immunoevasin. $J$ Immunol. 2010;185(1):28-32. Epub 2010/06/04. doi: 10.4049/jimmunol.1000240. PubMed PMID: 20519648.

40. Carayannopoulos LN, Naidenko OV, Kinder J, Ho EL, Fremont DH, Yokoyama WM. Ligands for murine NKG2D display heterogeneous binding behavior. European journal of immunology. 2002;32(3):597-605. Epub 2002/02/22. doi: 10.1002/15214141(200203)32:3\&\#60;597::AID-IMMU597\&\#62;3.0.CO;2-E. PubMed PMID: 11857333.

41. Mistry AR, O'Callaghan CA. Regulation of ligands for the activating receptor NKG2D. Immunology. 2007;121(4):439-47. Epub 2007/07/07. doi: 10.1111/j.1365-2567.2007.02652.x. PubMed PMID: 17614877; PubMed Central PMCID: PMC2265965.

42. Strong RK, McFarland BJ. NKG2D and Related Immunoreceptors. Adv Protein Chem. 2004;68:281-312. Epub 2004/10/27. doi: 10.1016/S0065-3233(04)68008-9. PubMed PMID: 15500864 .

43. Deng L, Mariuzza RA. Structural basis for recognition of MHC and MHC-like ligands by natural killer cell receptors. Semin Immunol. 2006;18(3):159-66. Epub 2006/06/02. doi: 10.1016/j.smim.2006.03.004. PubMed PMID: 16737824; PubMed Central PMCID: PMC2519613.

44. Li P, McDermott G, Strong RK. Crystal structures of RAE-1beta and its complex with the activating immunoreceptor NKG2D. Immunity. 2002;16(1):77-86. Epub 2002/02/05. PubMed PMID: 11825567.

45. Li P, Morris DL, Willcox BE, Steinle A, Spies T, Strong RK. Complex structure of the activating immunoreceptor NKG2D and its MHC class I-like ligand MICA. Nature immunology. 2001;2(5):443-51. Epub 2001/04/27. doi: 10.1038/87757. PubMed PMID: 11323699.

46. Li P, Willie ST, Bauer S, Morris DL, Spies T, Strong RK. Crystal structure of the MHC class I homolog MIC-A, a gammadelta T cell ligand. Immunity. 1999;10(5):577-84. Epub 1999/06/15. PubMed PMID: 10367903. 
47. Radaev S, Rostro B, Brooks AG, Colonna M, Sun PD. Conformational plasticity revealed by the cocrystal structure of NKG2D and its class I MHC-like ligand ULBP3. Immunity. 2001;15(6):1039-49. Epub 2002/01/05. PubMed PMID: 11754823.

48. Adams EJ, Luoma AM. The adaptable major histocompatibility complex (MHC) fold: structure and function of nonclassical and MHC class I-like molecules. Annu Rev Immunol. 2013;31:529-61. Epub 2013/01/10. doi: 10.1146/annurev-immunol-032712-095912. PubMed PMID: 23298204.

49. McFarland BJ, Kortemme T, Yu SF, Baker D, Strong RK. Symmetry recognizing asymmetry: analysis of the interactions between the C-type lectin-like immunoreceptor NKG2D and MHC class I-like ligands. Structure. 2003;11(4):411-22. Epub 2003/04/08. PubMed PMID: 12679019.

50. Chapman JL, Nichols DK, Martinez MJ, Raymond JW. Animal models of orthopoxvirus infection. Veterinary pathology. 2010;47(5):852-70. doi: 10.1177/0300985810378649. PubMed PMID: 20682806.

51. Lefkowitz EJ, Upton C, Changayil SS, Buck C, Traktman P, Buller RM. Poxvirus Bioinformatics Resource Center: a comprehensive Poxviridae informational and analytical resource. Nucleic acids research. 2005;33(Database issue):D311-6. Epub 2004/12/21. doi: 10.1093/nar/gki110. PubMed PMID: 15608205; PubMed Central PMCID: PMC540064.

52. Strong RK. Asymmetric ligand recognition by the activating natural killer cell receptor NKG2D, a symmetric homodimer. Molecular immunology. 2002;38(14):1029-37. Epub 2002/04/17. PubMed PMID: 11955595.

53. Radaev S, Sun PD. Structure and function of natural killer cell surface receptors. Annu Rev Biophys Biomol Struct. 2003;32:93-114. Epub 2002/12/10. doi: 10.1146/annurev.biophys.32.110601.142347. PubMed PMID: 12471063.

54. Copeland RA, Pompliano DL, Meek TD. Drug-target residence time and its implications for lead optimization. Nat Rev Drug Discov. 2006;5(9):730-9. Epub 2006/08/05. doi: 10.1038/nrd2082. PubMed PMID: 16888652.

55. O'Callaghan CA, Cerwenka A, Willcox BE, Lanier LL, Bjorkman PJ. Molecular competition for NKG2D: $\mathrm{H} 60$ and RAE1 compete unequally for NKG2D with dominance of $\mathrm{H} 60$. Immunity. 2001;15(2):201-11. Epub 2001/08/25. PubMed PMID: 11520456.

56. Groh V, Bruhl A, El-Gabalawy H, Nelson JL, Spies T. Stimulation of T cell autoreactivity by anomalous expression of NKG2D and its MIC ligands in rheumatoid arthritis. Proceedings of the National Academy of Sciences of the United States of America. 2003;100(16):9452-7. Epub 2003/07/25. doi: 10.1073/pnas.1632807100. PubMed PMID: 12878725; PubMed Central PMCID: PMC170939.

57. Hue S, Mention JJ, Monteiro RC, Zhang S, Cellier C, Schmitz J, et al. A direct role for NKG2D/MICA interaction in villous atrophy during celiac disease. Immunity. 2004;21(3):367-77. Epub 2004/09/11. doi: 10.1016/j.immuni.2004.06.018. PubMed PMID: 15357948.

58. Meresse B, Chen Z, Ciszewski C, Tretiakova M, Bhagat G, Krausz TN, et al. Coordinated induction by IL15 of a TCR-independent NKG2D signaling pathway converts CTL into lymphokine-activated killer cells in celiac disease. Immunity. 2004;21(3):357-66. Epub 2004/09/11. doi: 10.1016/j.immuni.2004.06.020. PubMed PMID: 15357947.

59. Ogasawara K, Hamerman JA, Hsin H, Chikuma S, Bour-Jordan H, Chen T, et al. Impairment of NK cell function by NKG2D modulation in NOD mice. Immunity. 2003;18(1):41-51. Epub 2003/01/18. PubMed PMID: 12530974.

60. Hahn M, Nicholson MJ, Pyrdol J, Wucherpfennig KW. Unconventional topology of self peptide-major histocompatibility complex binding by a human autoimmune T cell receptor. Nature immunology. 2005;6(5):490-6. Epub 2005/04/12. doi: 10.1038/ni1187. PubMed PMID: 15821740; PubMed Central PMCID: PMC3415330.

61. Sethi DK, Schubert DA, Anders AK, Heroux A, Bonsor DA, Thomas CP, et al. A highly tilted binding mode by a self-reactive $T$ cell receptor results in altered engagement of peptide and MHC. The Journal of experimental medicine. 2011;208(1):91-102. Epub 2011/01/05. doi: 10.1084/jem.20100725. PubMed PMID: 21199956; PubMed Central PMCID: PMC3023130.

62. Wucherpfennig KW, Call MJ, Deng L, Mariuzza R. Structural alterations in peptide-MHC recognition by self-reactive $T$ cell receptors. Curr Opin Immunol. 2009;21(6):590-5. Epub 
1

2

3

4

5

6

53

54

2009/08/25. doi: 10.1016/j.coi.2009.07.008. PubMed PMID: 19699075; PubMed Central PMCID: PMC2787854.

63. Yin Y, Li Y, Mariuzza RA. Structural basis for self-recognition by autoimmune T-cell receptors. Immunological reviews. 2012;250(1):32-48. Epub 2012/10/11. doi: 10.1111/imr.12002. PubMed PMID: 23046121.

64. Adams JJ, Narayanan S, Liu B, Birnbaum ME, Kruse AC, Bowerman NA, et al. T cell receptor signaling is limited by docking geometry to peptide-major histocompatibility complex. Immunity. 2011;35(5):681-93. Epub 2011/11/22. doi: 10.1016/j.immuni.2011.09.013. PubMed PMID: 22101157; PubMed Central PMCID: PMC3253265.

65. Schubert DA, Gordo S, Sabatino JJ, Jr., Vardhana S, Gagnon E, Sethi DK, et al. Selfreactive human $\mathrm{CD} 4 \mathrm{~T}$ cell clones form unusual immunological synapses. The Journal of experimental medicine. 2012;209(2):335-52. Epub 2012/02/09. doi: 10.1084/jem.20111485. PubMed PMID: 22312112; PubMed Central PMCID: PMC3280872.

66. Li Y, Yin Y, Mariuzza RA. Structural and biophysical insights into the role of CD4 and CD8 in $T$ cell activation. Front Immunol. 2013;4:206. Epub 2013/07/26. doi: 10.3389/fimmu.2013.00206. PubMed PMID: 23885256; PubMed Central PMCID: PMC3717711.

67. Campbell JA, Davis RS, Lilly LM, Fremont DH, French AR, Carayannopoulos LN. Cutting Edge: FcR-Like 5 on Innate B Cells Is Targeted by a Poxvirus MHC Class I-Like Immunoevasin. The Journal of Immunology. 2010;185(1):28-32. doi: 10.4049/jimmunol.1000240.

68. Zafirova B, Mandarić S, Antulov R, Krmpotić A, Jonsson H, Yokoyama WM, et al. Altered NK cell development and enhanced NK cell-mediated resistance to mouse cytomegalovirus in NKG2D-deficient mice. Immunity. 2009;31(2):270-82. doi: 10.1016/j.immuni.2009.06.017. PubMed PMID: 19631564.

69. Earl PL, Cooper N, Wyatt LS, Moss B, Carroll MW. Preparation of cell cultures and vaccinia virus stocks. Current protocols in protein science / editorial board, John E Coligan [et al]. 2001;Chapter 5:Unit5.12. doi: 10.1002/0471140864.ps0512s13. PubMed PMID: 18429178.

70. Earl PL, Cooper N, Wyatt LS, Moss B, Carroll MW. Preparation of cell cultures and vaccinia virus stocks. Current protocols in protein science / editorial board, John E Coligan [et al]. 2001;Chapter 5:Unit5 12. Epub 2008/04/23. doi: 10.1002/0471140864.ps0512s13. PubMed PMID: 18429178.

71. Falkner FG, Moss B. Transient dominant selection of recombinant vaccinia viruses. Journal of virology. 1990;64(6):3108-11. Epub 1990/06/01. PubMed PMID: 2159565; PubMed Central PMCID: PMC249504.

72. Kato SE, Greco FA, Damaso CR, Condit RC, Moussatche N. An alternative genetic method to test essential vaccinia virus early genes. Journal of virological methods. 2004;115(1):31-40. Epub 2003/12/06. PubMed PMID: 14656458.

73. Tomschy A, Fauser C, Landwehr R, Engel J. Homophilic adhesion of E-cadherin occurs by a co-operative two-step interaction of N-terminal domains. EMBO J. 1996;15(14):3507-14. Epub 1996/07/15. PubMed PMID: 8670853; PubMed Central PMCID: PMCPMC451947.

74. Otwinowski Z, Minor W. Processing of X-ray diffraction data collected in oscillation mode. Macromolecular Crystallography, Pt A. 1997;276:307-26. PubMed PMID: ISI:A1997BH42P00020. 75. Adams PD, Grosse-Kunstleve RW, Hung LW, loerger TR, McCoy AJ, Moriarty NW, et al. PHENIX: building new software for automated crystallographic structure determination. Acta crystallographica Section D, Biological crystallography. 2002;58(Pt 11):1948-54. Epub 2002/10/24. PubMed PMID: 12393927.

76. Emsley P, Cowtan K. Coot: model-building tools for molecular graphics. Acta crystallographica Section D, Biological crystallography. 2004;60(Pt 12 Pt 1):2126-32. Epub 2004/12/02. doi: 10.1107/S0907444904019158. PubMed PMID: 15572765.

77. Chen VB, Arendall WB, 3rd, Headd JJ, Keedy DA, Immormino RM, Kapral GJ, et al. MolProbity: all-atom structure validation for macromolecular crystallography. Acta crystallographica Section D, Biological crystallography. 2010;66(Pt 1):12-21. Epub 2010/01/09. doi: 10.1107/S0907444909042073. PubMed PMID: 20057044; PubMed Central PMCID: PMC2803126.

78. Schrodinger, LLC. The PyMOL Molecular Graphics System, Version 1.3r1. 2010. 
1

\section{4}

79. Laskowski RA, Swindells MB. LigPlot+: multiple ligand-protein interaction diagrams for drug discovery. Journal of chemical information and modeling. 2011;51(10):2778-86. Epub 2011/09/17. doi: 10.1021/ci200227u. PubMed PMID: 21919503.

80. Krissinel E, Henrick K. Inference of macromolecular assemblies from crystalline state. Journal of molecular biology. 2007;372(3):774-97. Epub 2007/08/08. doi: 10.1016/j.jmb.2007.05.022. PubMed PMID: 17681537.

81. Lawrence MC, Colman PM. Shape complementarity at protein/protein interfaces. Journal of molecular biology. 1993;234(4):946-50. Epub 1993/12/20. doi: 10.1006/jmbi.1993.1648. PubMed PMID: 8263940.

82. Morin A, Eisenbraun B, Key J, Sanschagrin PC, Timony MA, Ottaviano M, et al. Collaboration gets the most out of software. eLife. 2013;2:e01456. Epub 2013/09/17. doi: 10.7554/eLife.01456. PubMed PMID: 24040512; PubMed Central PMCID: PMC3771563.

83. Ashkenazy H, Erez E, Martz E, Pupko T, Ben-Tal N. ConSurf 2010: calculating evolutionary conservation in sequence and structure of proteins and nucleic acids. Nucleic acids research. 2010;38(Web Server issue):W529-33. Epub 2010/05/19. doi: 10.1093/nar/gkq399. PubMed PMID: 20478830; PubMed Central PMCID: PMC2896094.

84. Landau M, Mayrose I, Rosenberg Y, Glaser F, Martz E, Pupko T, et al. ConSurf 2005: the projection of evolutionary conservation scores of residues on protein structures. Nucleic acids research. 2005;33(Web Server issue):W299-302. Epub 2005/06/28. doi: 10.1093/nar/gki370. PubMed PMID: 15980475; PubMed Central PMCID: PMC1160131.

85. Glaser F, Pupko T, Paz I, Bell RE, Bechor-Shental D, Martz E, et al. ConSurf: identification of functional regions in proteins by surface-mapping of phylogenetic information. Bioinformatics. 2003;19(1):163-4. Epub 2002/12/25. PubMed PMID: 12499312.

86. Celniker G, Nimrod G, Ashkenazy H, Glaser F, Martz E, Mayrose I, et al. ConSurf: Using Evolutionary Data to Raise Testable Hypotheses about Protein Function. Isr J Chem. 2013;53(34):199-206. doi: Doi 10.1002/ljch.201200096. PubMed PMID: ISI:000317859800010.

87. Dokun AO, Kim S, Smith HR, Kang HS, Chu DT, Yokoyama WM. Specific and nonspecific NK cell activation during virus infection. Nat Immunol. 2001;2(10):951-6. doi: 10.1038/ni714. PubMed PMID: 11550009.

88. Nybakken GE, Oliphant T, Johnson S, Burke S, Diamond MS, Fremont DH. Structural basis of West Nile virus neutralization by a therapeutic antibody. Nature. 2005;437(7059):764-9. Epub 2005/09/30. doi: nature03956 [pii] 10.1038/nature03956. PubMed PMID: 16193056.

89. Zhang X, Goncalves R, Mosser DM. The isolation and characterization of murine macrophages. Curr Protoc Immunol. 2008;Chapter 14:Unit 14.1. doi: 10.1002/0471142735.im1401s83. PubMed PMID: 19016445.

90. Stewart DE, Sarkar A, Wampler JE. Occurrence and role of cis peptide bonds in protein structures. Journal of molecular biology. 1990;214(1):253-60. Epub 1990/07/05. doi: 10.1016/0022-2836(90)90159-J. PubMed PMID: 2370664.

91. Craveur P, Joseph AP, Poulain P, de Brevern AG, Rebehmed J. Cis-trans isomerization of omega dihedrals in proteins. Amino Acids. 2013;45(2):279-89. Epub 2013/06/04. doi: 10.1007/s00726-013-1511-3. PubMed PMID: 23728840. 


\section{Figure Legends}

3 Figure 1. Cowpox virus lacking OMCP is significantly attenuated in vivo. WT

$4 \operatorname{CPXV}(\mathbf{A})$ is more virulent than $\triangle \mathrm{V} 018 \mathrm{CPXV}(\mathbf{B})$, as evidenced by increased lethality at

5 all tested doses. The revertant CPXV control (C) phenocopies WT CPXV as is

6 expected. 8-12 week old female WT B6 mice were infected with $2 \times 10^{6}$ (solid line), $1 \times 10^{6}$

7 (dashed line), or $0.6 \times 10^{6}$ (dotted line) of the indicated CPXV strain, and survival was

8 assessed daily for 28 days. Data are aggregated from two-seven independent

9 experiments with 5-10 mice per group.

11 Figure 2. The structure of OMCP in complex with NKG2D. (A) OMCP bound to

12 NKG2D. OMCP is colored magenta and the protomers of NKG2D are colored cyan ("A")

13 and yellow ("B"). NKG2D ${ }^{A}$ makes contacts primarily with the $\mathrm{H} 2 \mathrm{a}$ helix and NKG2D

14 with $\mathrm{H} 2 \mathrm{~b}$. Mutations introduced to facilitate alternate crystal packing are shown in red.

15 The S193-S194 bond is shown as a ball on each NKG2D protomer. The asparagines of

16 putative hNKG2D glycosylation sites are shown in orange. The asparagine of the

17 confirmed N-glycan site of OMCP is shown green (data not shown) (B) View of the

18 interface between OMCP-NKG2D. The a2 domain of OMCP is shown in the front with

19 the a1 domain behind. OMCP and NKG2D are shown with cartoon representations for

20 the main chain, with the side chains of contact residues shown as sticks. Hydrogen

21 bonds and salt bridges are indicated with green dotted lines.

23 Figure 3. The interface of OMCP and NKG2D. (A) The local environment of the

24 OMCP-NKG2D binding interface surrounding the D132R residue. The D132R mutation

25 ablates OMCP-NKG2D binding. (B) APC labeled OMCP tetramers (solid line) were

26 used to stain splenic NK cells (NK1.1+, CD3-) and peritoneal B1-a B cells (CD19+, 
1 CD5+), Staining with APC labeled WNV DIII tetramer control shown in gray histograms.

2 Representative results from three independent experiments.

4 Figure 4. NKG2D mediates all of the virulence of OMCP during intranasal CPXV

5 infection. WT CPXV (solid line), $\triangle$ V018 CPXV (dashed line) and D132R OMCP CPXV

6 (dotted line) infected via the intranasal route differentially influence survival in (A) WT

7 B6, (B) NKG2D-deficient, and (C) FcRL5-deficient mice. Kaplan-Meier analysis shows

8 survival of female mice following intranasal infection with $2.5 \times 10^{4}$ pfu of the designated

9 CPXV strain. The data are aggregated from two to four independent experiments. The

10 Log-rank (Mantel-Cox) test was used in the comparison of all Kaplan Meier survival

11 curves. NS not significant, ${ }^{* *} p<0.01{ }^{* * *} p<0.001$

13 Figure 5. Glycosylated OMCP binds to NKG2D only. (A) Sorted Ba/Fc cells

14 transduced (EGFP positive) with NKG2D or FcRL5 were stained with biotinylated

15 monomeric OMCPs or with antibodies to NKG2D or FCRL5. A representative experiment

16 is shown. (B) Pentamers of OMCP, (D132R) OMCP, or ULBP3 were incubated with

17 ficoll-purified human PBMCs. PBMCs were stained with antibodies to CD56, CD19,

18 CD3, and CD16. NK (CD56+, CD3-), T (CD3+), and B (CD19+, CD3-) cells were then

19 assessed by flow cytometry for protein binding. Representative results from four

20 independent experiments.

22 Figure 6. Differences in the $\beta 5$ '- $\beta 5$ loop (L2) of human and murine NKG2D. (A-B)

23 Superimposition of mNKG2D (grey) (PDB ID: 1HQ8) with the structure of OMCP-

24 hNKG2D (yellow and cyan). Core binding residues Y152 (Y168) and Y199 (Y215) are

25 positionally conserved, while core binding residue M184 (I200) is not. (C) Surface

26 representation of OMCP (magenta) interacting with the $\beta 5$ '- $\beta 5$ loop. (D) Conservation of 
1 M184 and Q185. Only the NKG2D of mice, rats, guinea pigs, and flying foxes (not

2 shown) differ. Conservation score is as computed by the ConSurf server.

4 Figure 7. A novel NKG2D binding adaptation. Surface representation of NKG2D and

5 surface and cartoon representations of OMCP, MICA and ULBP3. Buried surface areas

6 for $\mathrm{NKG}_{2} \mathrm{D}^{\mathrm{A}}$ and $\mathrm{NKG} 2 \mathrm{D}^{\mathrm{B}}$ are indicated in cyan and yellow, respectively. Buried surface

7 area by NKG2D is indicated for OMCP (magenta), MICA (green), and ULBP3 (orange).

8 The core binding residues of NKG2D and NKG2D-binding elements of NKG2DLs are

9 indicated. Alignment by secondary structure of NKG2DLs (PDB ID: OMCP (4FFE),

10 MICA (1HYR), MICB (1JE6), ULBP3 (1KCG) and RAE-1 $\beta$ (1JSK)). Contact residues are

11 indicated for OMCP (magenta), MICA (green), ULBP3 (orange) and RAE-1 $\beta$ (bold and

12 italics). Secondary structure elements are noted above the sequence (arrow for beta

13 sheets, cylinders for alpha helices). Predicted glycan sites are highlighted in black.

15 Figure 8. Activation of NK cells by cell-associated OMCP. Model depicting NKG2D

16 interaction with (A) host, (B) cancer-induced, (C) viral, or (D) chimeric ligands. Binding

17 interactions that lead to NKG2D-mediated signaling are indicated by DAP10 tyrosine

18 phosphorylation (red filled circles). (E) IL-2-activated splenocytes were used as

19 cytotoxic effectors against stably transduced $\mathrm{Ba} / \mathrm{F} 3$ cell lines. Splenocytes were

20 activated with $200 \mathrm{U} / \mathrm{ml}$ of IL-2 for 24 hours. Labeled target cells were co-incubated with

21 activated splenocytes for 4 hours at effector:target ratios of 10:1, 20:1, and 40:1. Killing

22 was measured by incorporation of 7AAD by CFSE-labeled target cells using flow

23 cytometry. Representative data from five independent experiments is shown

25 Figure S1. $\Delta$ V018 virus and D132R virus do not have a growth defect in vitro.

26 Multi-step growth curves for WT CPXV, $\triangle$ V018, D132R, and revertant viruses show that 
1 all four cowpox virus strains have similar replication kinetics in a multi-step growth curve.

2 B-SC-1 cells were infected at an $\mathrm{MOI}$ of 0.01 with the indicated viruses. Infected cells

3 were harvested at the indicated time points and freeze-thawed three times. Lysates

4 were titered by plaque assay on B-SC-1 monolayers. Results are representative of three

5 experiments done in duplicate.

6

$7 \quad$ Figure S2. Electron density supporting a cis peptide conformation. Stereo view of

8 the $\beta 5-\beta 6$ loop of hNKG2D. Residues 193-Ala-Ser-Ser-Phe-Lys-197 is displayed for the

9 OMCP-hNKG2D structure (yellow) and the structure of hNKG2D alone (grey). The 2Fo-

10 Fc map for OMCP-hNKG2D is displayed at $2 \sigma$. Cis conformations are underrepresented

11 in crystal structures and are often under reported due to resolution limits and

12 assumptions made during structure refinement [90, 91].

14 Figure S3. Glycosylation of mammalian-expressed OMCP. OMCP has two putative

15 N-linked glycosylation sites, N12 and N88 (A) WT, glycosylated OMCP migrates slowly

16 as a diffuse band. OMCP mutated at either N12 or N12/N88 migrate quickly as sharp

17 bands. Mutation of N88 alone does not effect OMCP migration. (B) N-linked glycans

18 were completely removed from $1 \mathrm{ug}$ of OMCP by incubation with $10 \mathrm{U}$ Endo- $\mathrm{F}$ in $50 \mathrm{mM}$

19 sodium phosphate (pH7.5) at $37 \mathrm{C}$ for $16 \mathrm{~h}$.

\begin{tabular}{|c|c|}
\hline \multicolumn{2}{|c|}{ Table 1: Data collection and refinement statistics ${ }^{\mathrm{a}}$} \\
\hline \multicolumn{2}{|l|}{ Data collection } \\
\hline Space group & $\mathrm{P} 2_{1}$ \\
\hline \multicolumn{2}{|l|}{ Cell dimensions } \\
\hline$a, b, c(A ̈)$ & $43.3,101.1,91.4$ \\
\hline$\alpha \beta \gamma\left({ }^{\circ}\right)$ & $90.0,91.6,90.0$ \\
\hline Resolution $(\AA ̊)$ & $50-2.0(2.07-2.00)$ \\
\hline$R_{\text {sym }}$ & $11.8(48.5)$ \\
\hline $1 / \sigma$ & $14.5(3.8)$ \\
\hline
\end{tabular}




\begin{tabular}{|c|c|}
\hline $\begin{array}{l}\text { Completeness (\%) } \\
\text { Redundancy }\end{array}$ & $\begin{array}{l}93.5(91.5) \\
6.2(5.3)\end{array}$ \\
\hline \multicolumn{2}{|l|}{ Refinement } \\
\hline Resolution (Ă) & $44-2.0$ \\
\hline Total reflections & 309693 \\
\hline Unique reflection & 50139 \\
\hline$R_{\text {work }}$ & $16.6 \%(21.0 \%)$ \\
\hline$R_{\text {free }}$ & $21.4 \%(29.5 \%)$ \\
\hline Wilson B-factor & 21.62 \\
\hline Protein residues & 791 \\
\hline Water molecules & 524 \\
\hline \multicolumn{2}{|l|}{ R.M.S. deviations } \\
\hline Bond lengths $(\AA)$ & 0.003 \\
\hline Bond angles $\left({ }^{\circ}\right)$ & 0.79 \\
\hline
\end{tabular}

1 as defined by PHENIX [75]

\begin{tabular}{|c|c|c|}
\hline NKG2D-A & OMCP & Bond type \\
\hline Lys150 & Asp132 & Salt bridge \\
\hline Lys150 & Trp127 & $\mathrm{H}$ bond \\
\hline Lys150 & Trp127 & $\Phi(3)$ \\
\hline Ser151 & Lys126 & $\mathrm{H}$ bond \\
\hline Ser151 & Trp127 & $\Phi(1)$ \\
\hline Tyr152 & Phe122 & $\mathrm{H}$ bond \\
\hline Tyr152 & Phe122 & $\Phi(9)$ \\
\hline Tyr152 & Lys126 & $\Phi(5)$ \\
\hline Met184 & Thr118 & $\mathrm{H}$ bond \\
\hline Met184 & Thr119 & $\Phi(1)$ \\
\hline Met184 & Phe122 & $\Phi(5)$ \\
\hline Gln185 & Arg66 & $\Phi(1)$ \\
\hline Leu191 & Phe122 & $\Phi(1)$ \\
\hline Tyr199 & Phe122 & $\Phi(4)$ \\
\hline Glu201 & Arg66 & Salt bridge \\
\hline Thr205 & Arg66 & $\mathrm{H}$ bond \\
\hline NKG2D-B & OMCP & Bond type \\
\hline
\end{tabular}




\begin{tabular}{|lll|} 
Leu148 & Trp127 & $\Phi(1)$ \\
Tyr151 & Glu131 & $\mathrm{H}$ bond \\
Tyr152 & Asp132 & $\mathrm{H}$ bond \\
Tyr152 & Glu131 & $\Phi(3)$ \\
Ile182 & Met135 & $\Phi(5)$ \\
Glu183 & Ile49 & $\Phi(2)$ \\
Met184 & Arg142 & Salt bridge \\
Met184 & Met135 & $\Phi(1)$ \\
Met184 & Arg138 & $\Phi(2)$ \\
Lys186 & Arg142 & $\mathrm{H}$ bond \\
Leu191 & Arg142 & $\Phi(1)$ \\
Glu201 & Met135 & $\Phi(1)$ \\
\hline
\end{tabular}

2 Hydrogen bonds ( $\mathrm{H}$ bonds), salt bridges and carbon-to-carbon hydrophobic interactions 3 (Ф) are shown for each contact residue. The number of hydrophobic interactions 4 between contact residues is designated in parenthesis. 


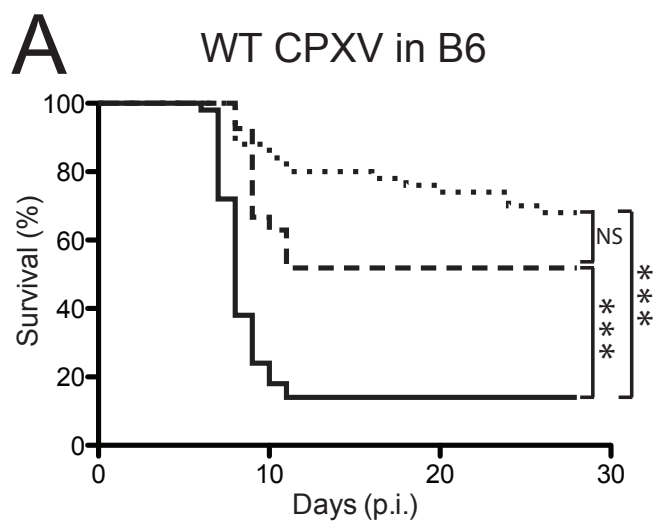

$2 \mathrm{e} 6$ WT in $\mathrm{B} 6 ; \mathrm{n}=50$

- 1 e6 WT in B6; $n=27$

-.. $0.6 \mathrm{e} 6 \mathrm{WT}$ in $\mathrm{B} 6 ; \mathrm{n}=50$
B

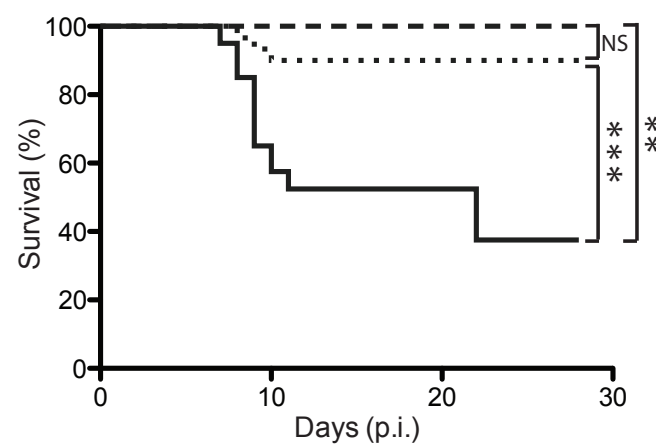

- 2 e $6 \Delta \mathrm{V} 018$ in $\mathrm{B} 6 ; \mathrm{n}=40$

- 1 e $6 \Delta V 018$ in $B 6 ; n=10$

..- $0.6 e 6 \Delta V 018$ in $B 6 ; n=30$
C Revertant CPXV in B6

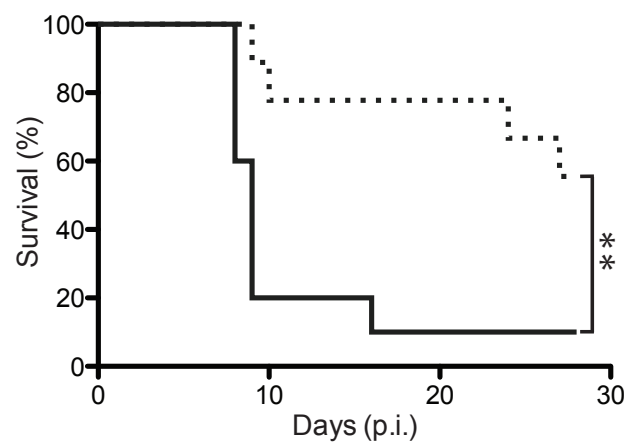

$2 \mathrm{e} 6$ rev in $\mathrm{B} 6 ; \mathrm{n}=10$

..- $0.6 e 6$ rev in $B 6 ; n=9$ 
bioRxiv preprint doi: https://doi.org/10.1101/796862; this version posted October 7, 2019. The copyright holder for this preprint (which was not certified by peer review) is the author/funder, who has granted bioRxiv a license to display the preprint in perpetuity. It is made available under aCC-BY-NC-ND 4.0 International license.

A

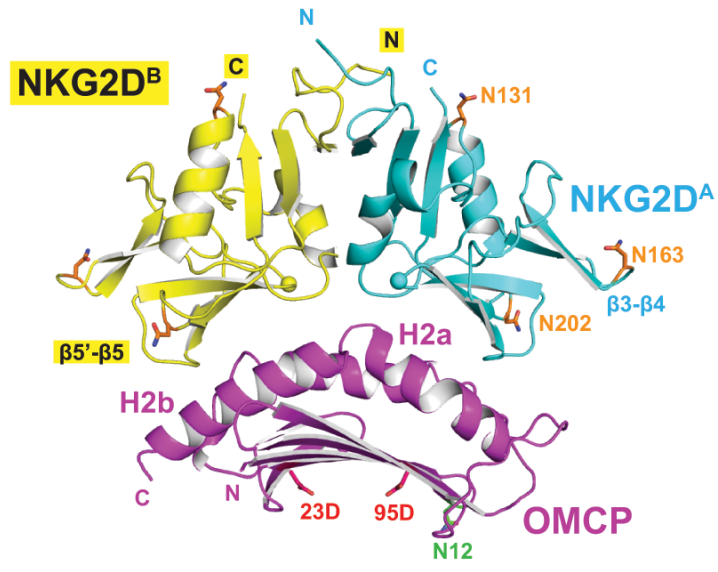

B

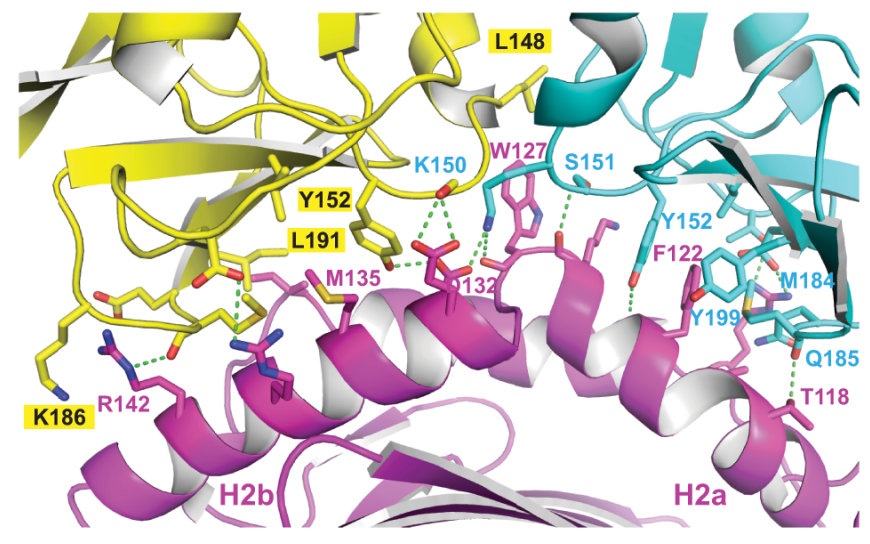


bioRxiv preprint doi: https://doi.org/10.1101/796862; this version posted October 7, 2019. The copyright holder for this preprint (which was not certified by peer review) is the author/funder, who has granted bioRxiv a license to display the preprint in perpetuity. It is made available under

A aCC-BY-NC-ND 4.0 International license.

Fig 3

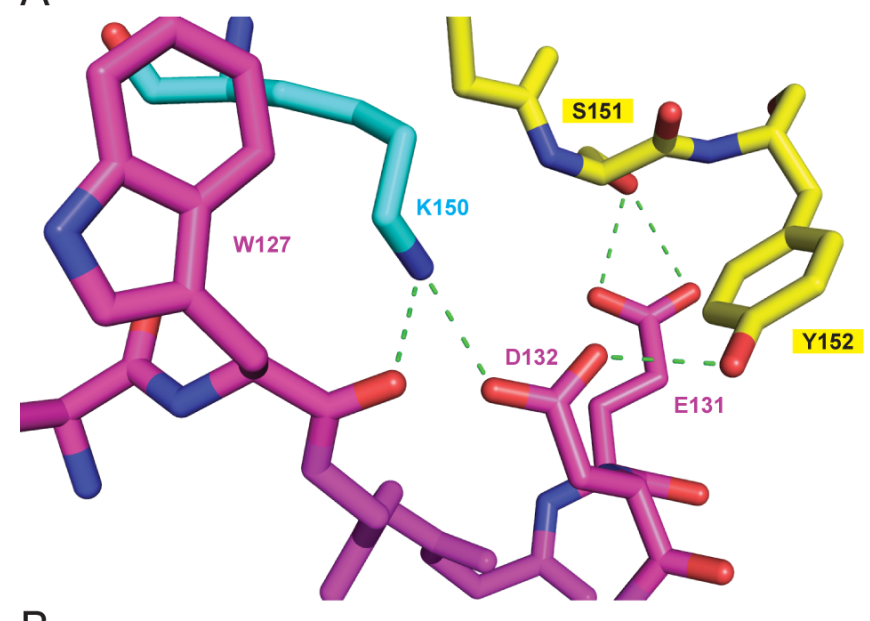

B

OMCP tetramer staining NK cells

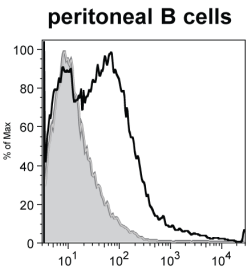

NKG2D-I-

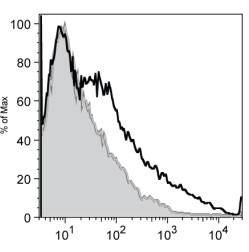

FCRL5-/-
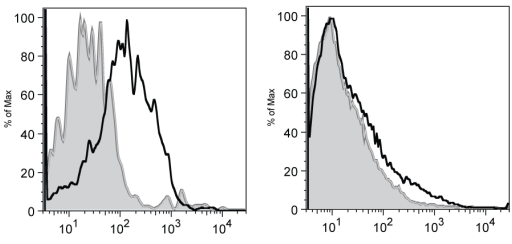

D132R tetramer staining
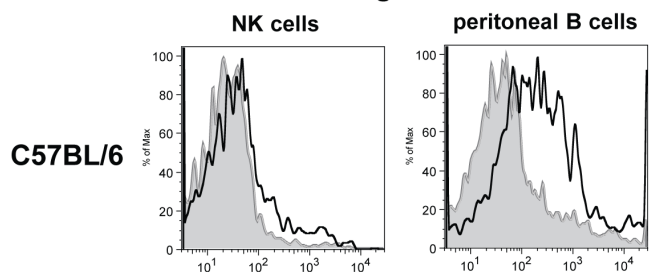

NKG2D-/-
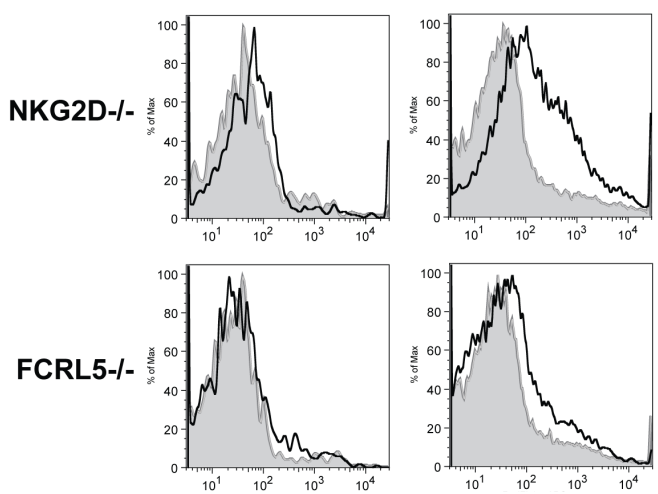


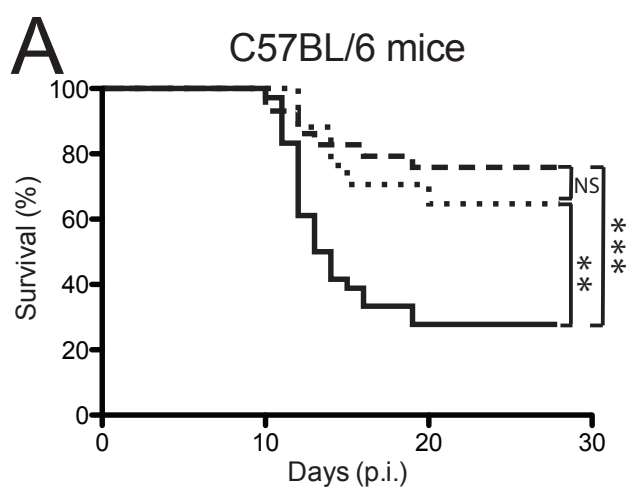

$2.5 \mathrm{e} 4 \mathrm{WT}$ in $\mathrm{B} 6 ; \mathrm{n}=31$

$-2.5 \mathrm{e} 4 \mathrm{~V} 018$ in $\mathrm{B} 6 ; \mathrm{n}=27$

-.. 2.5e4 D132R in $B 6 ; n=17$

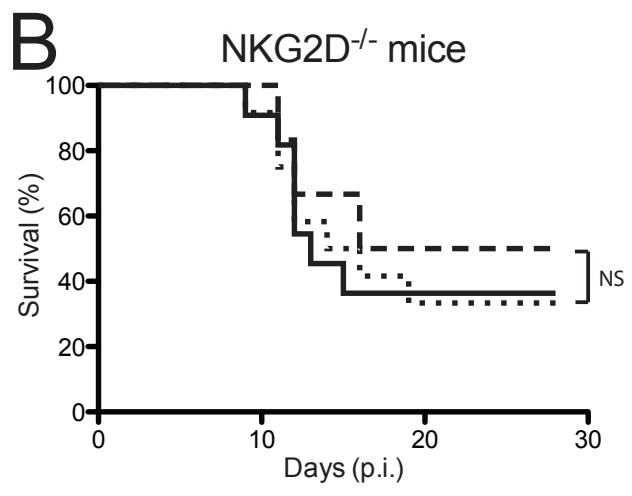

- 2.5e4 WT in NKG2D; $n=11$

- $2.5 \mathrm{e} 4 \Delta \mathrm{V} 018$ in NKG2D; $\mathrm{n}=11$

-. 2.5e4 D132R in NKG2D; $n=12$

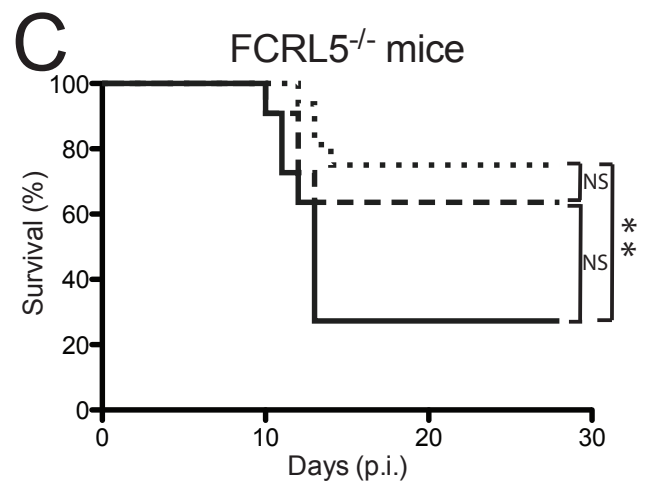

- 2.5e4 WT in FCRL5; $n=11$

- $2.5 \mathrm{e} 4 \Delta \mathrm{V} 018$ in FCRL5; $\mathrm{n}=11$

-.. 2.5e4 D132R in FCRL5; $n=16$ 
bioRxiv preprint doi: https://doi.org/10.1101/796862; this version posted October 7, 2019. The copyright holder for this preprint (which was not certified by peer review) is the author/funder, who has granted bioRxiv a license to display the preprint in perpetuity. It is made available under aCC-BY-NC-ND 4.0 International license.

A Ba/f3-NKG2D
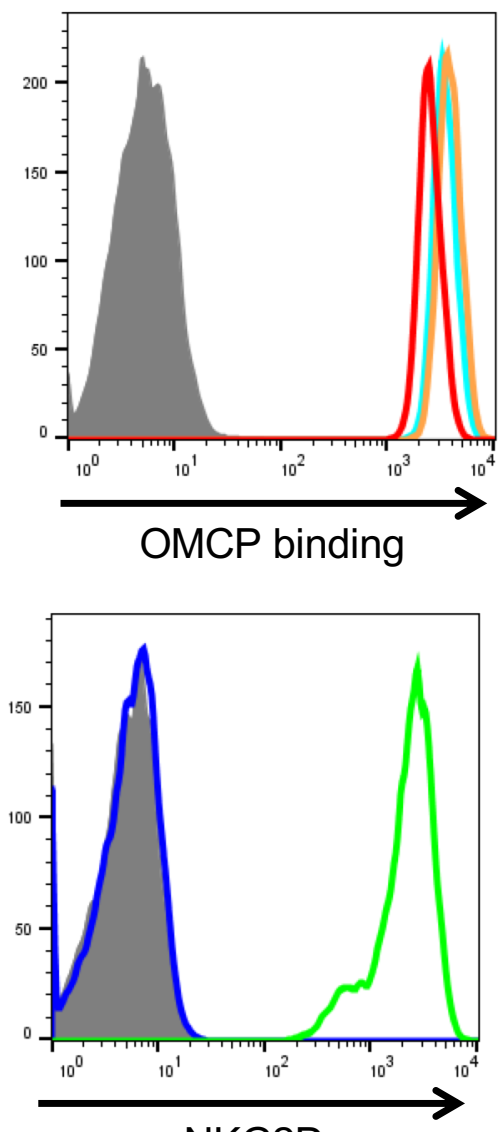

NKG2D

\section{Ba/f3-FcRL5}
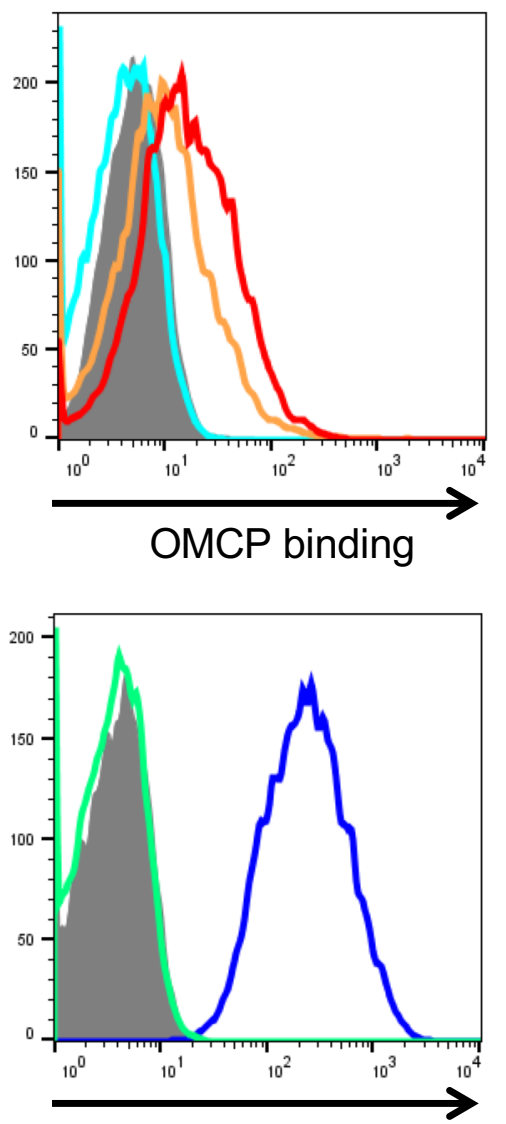

FcRL5
- PBS

- Mam-OMCP Mam-OMCP $\triangle \mathrm{CHO}$ Bac-OMCP

B

B NK cells

T cells

B cells

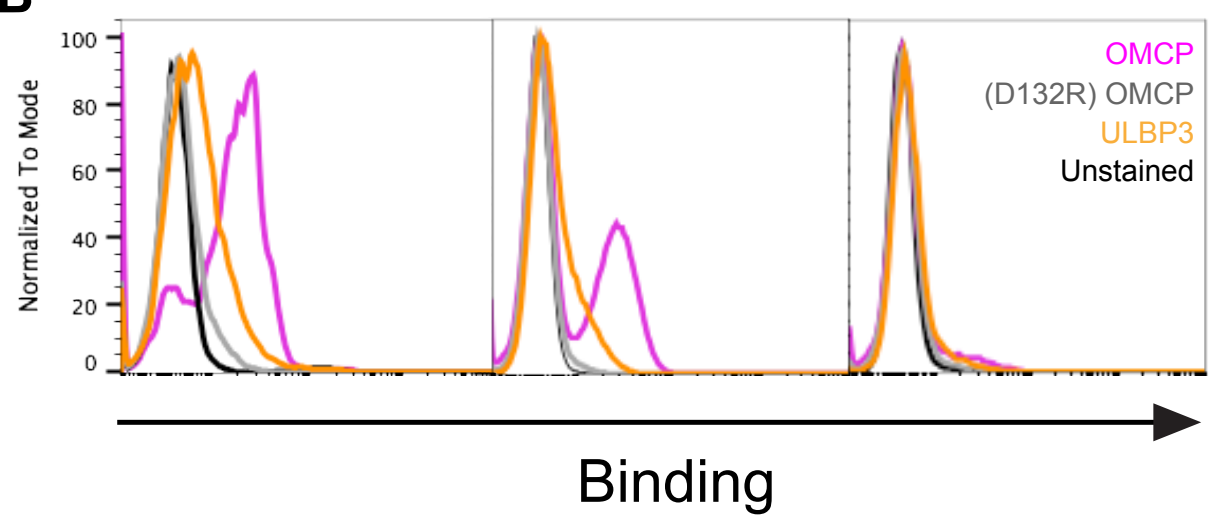


bioRxiv preprint doi: https://doi.org/10.1101/796862; this version posted October 7, 2019. The copyright holder for this preprint (which was not A certified by peer review) is the author/funder, who has granted bioRxiv a license to display the
hNKG2D

B
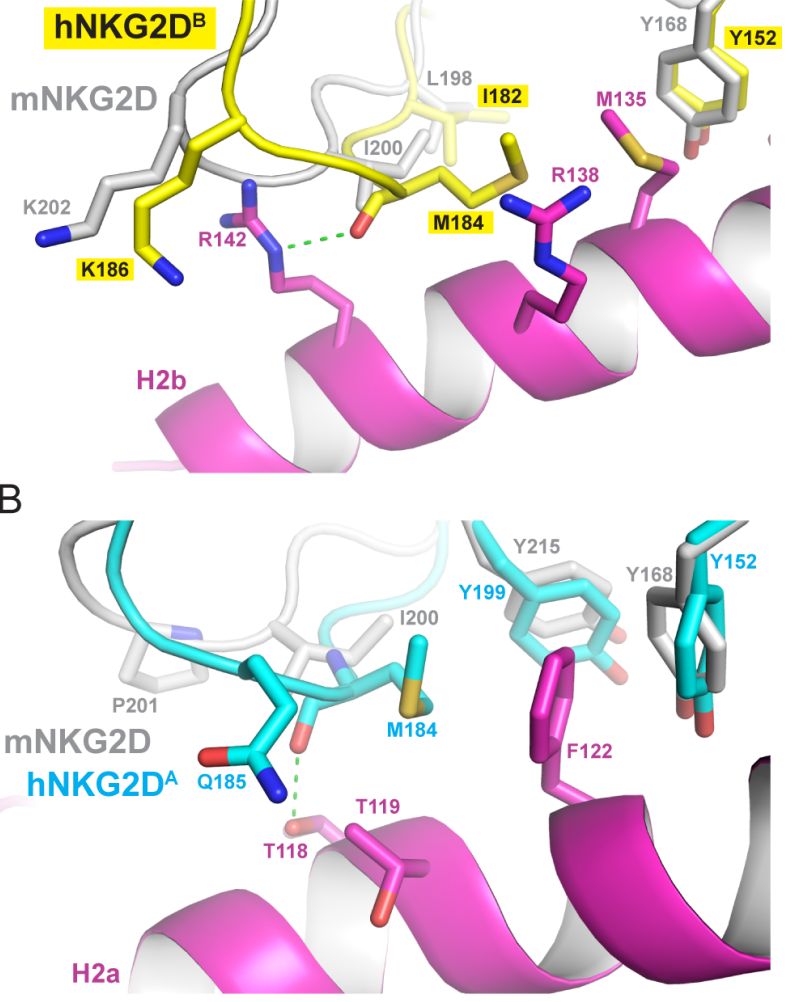

C

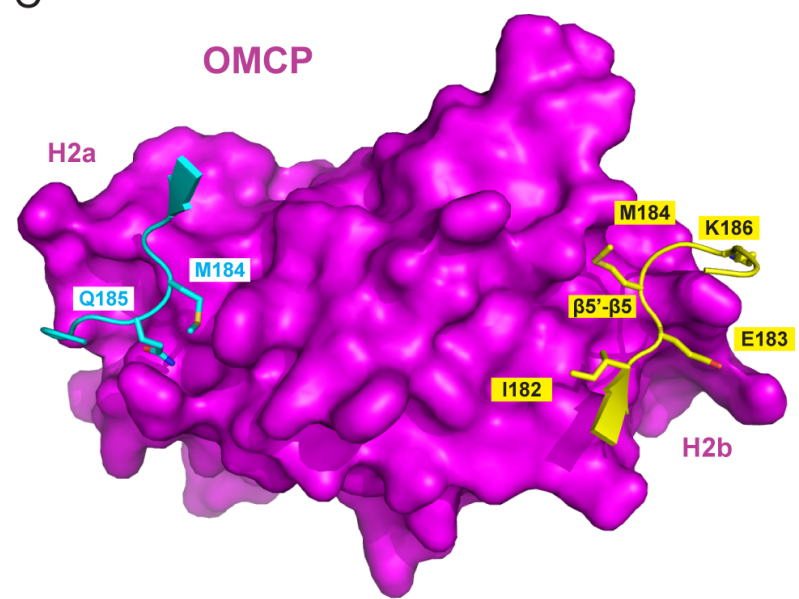

D

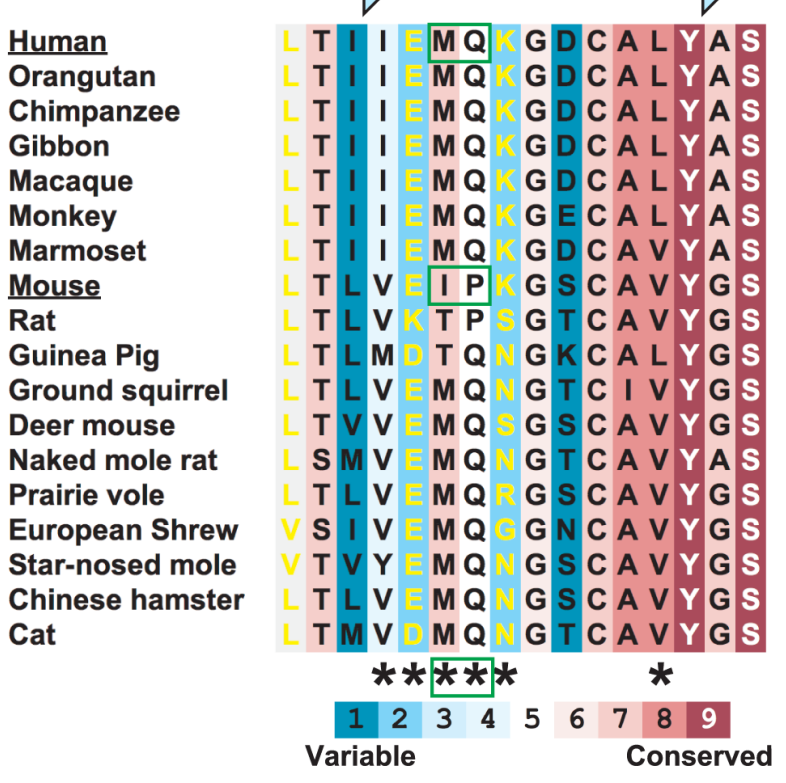


bioRxiv preprint doi: https://doi.org/10.1101/796862; this version posted October 7, 2019. The copyright holder for this preprint (which was not

\section{NKG2D}

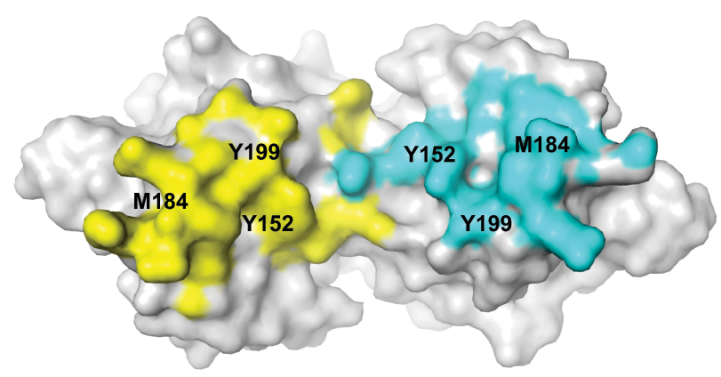

NKG2D

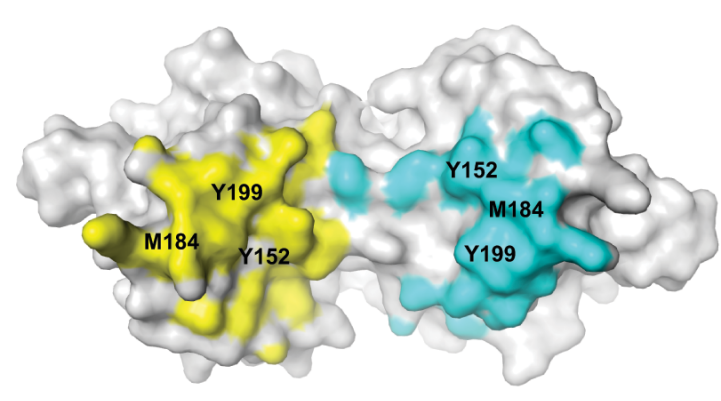

\section{NKG2D}

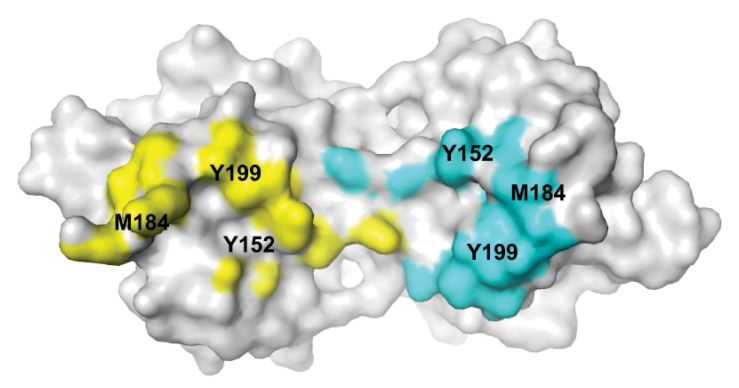

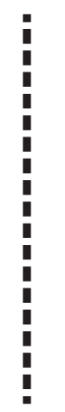

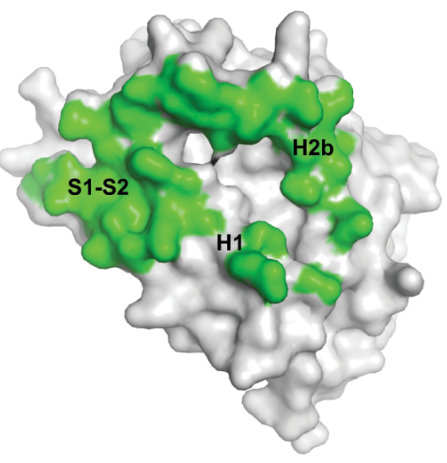

MICA

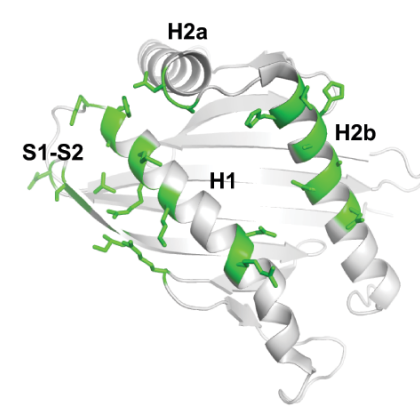

\section{ULBP3}
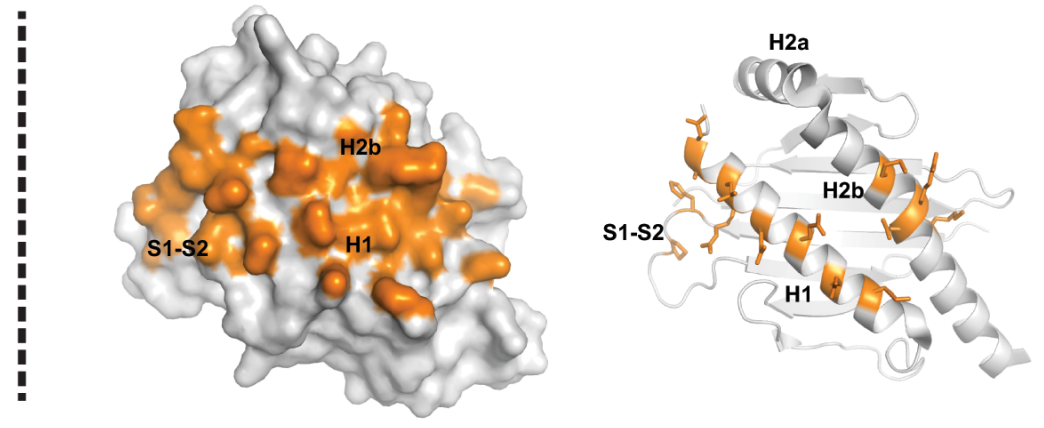

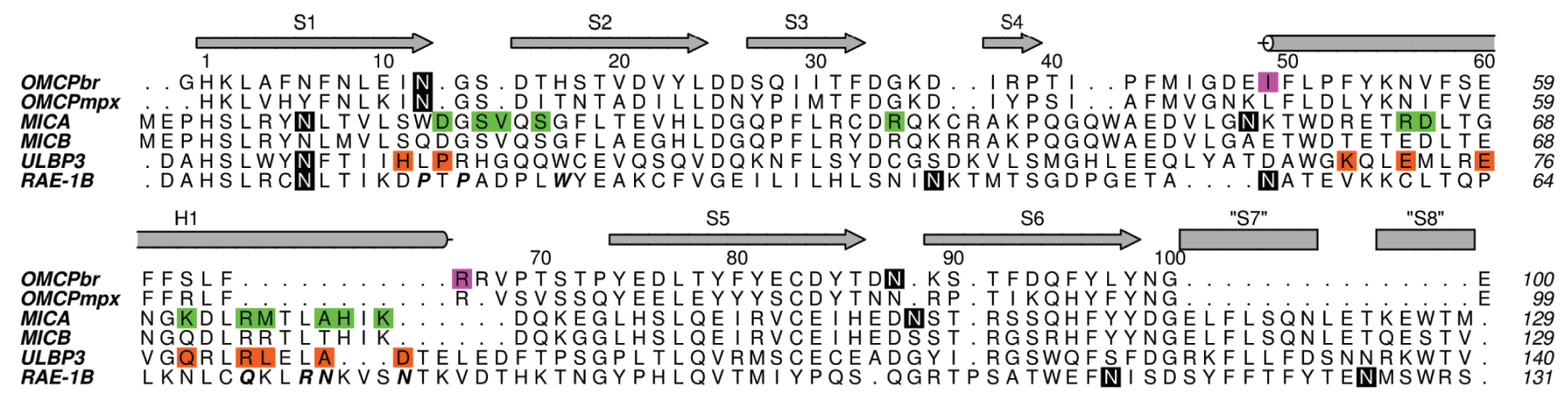

$\mathrm{H} 2 \mathrm{a}$

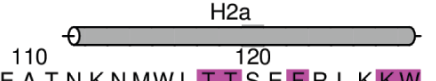

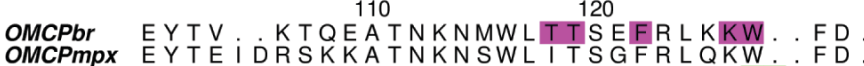


bioRxiv preprint doi: https://doi.org/10.1101/796862; this version posted October 7, 2019. The copyright holder for this preprint (which was not certified by peer review) is the author/funder, who has granted bioRxiv a license to display the preprint in perpetuity. It is made available under aCC-BY-NC-ND 4.0 International license.

Fig 8

A

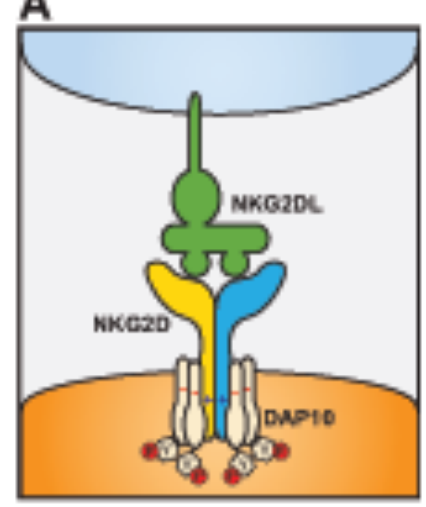

C

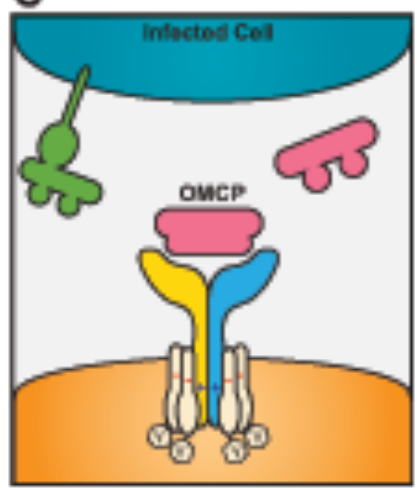

E
B

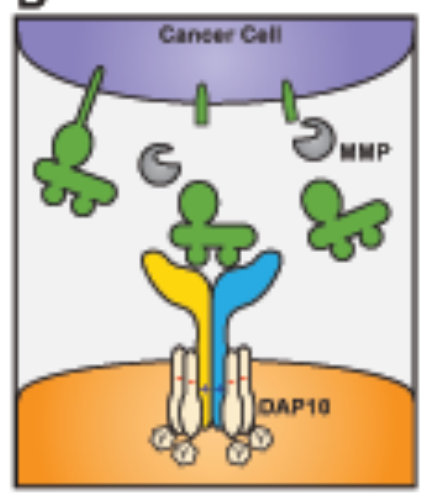

D

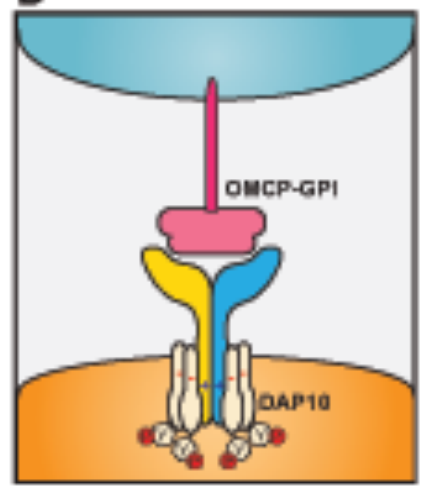

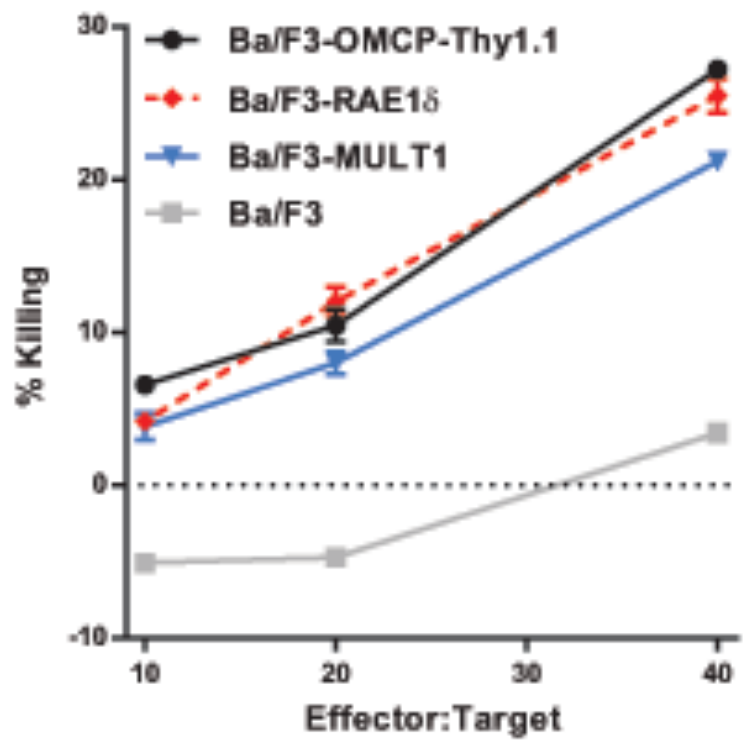


bioRxiv preprint doi: https://doi org/10.1101/796862; this version posted October 7, 2019. The copyright holder for this preprint (which was not certified by peer review) is the author/funder, who has granted bioRxiv a license to display the preprint in perpetuity. It is made available under aCC-BY-NC-ND 4.0 International license.

\section{Supplemental Figure 1}

\section{CPXV growth curve}

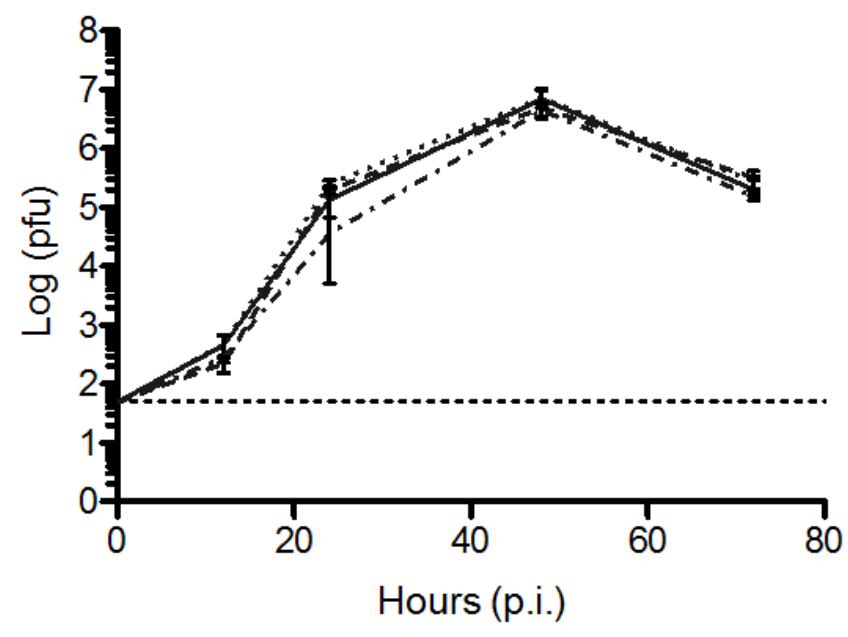

\footnotetext{
- WT CPXV

--- OMCP ko CPXV

… D132R CPXV

-.- Rev CPXV
} 


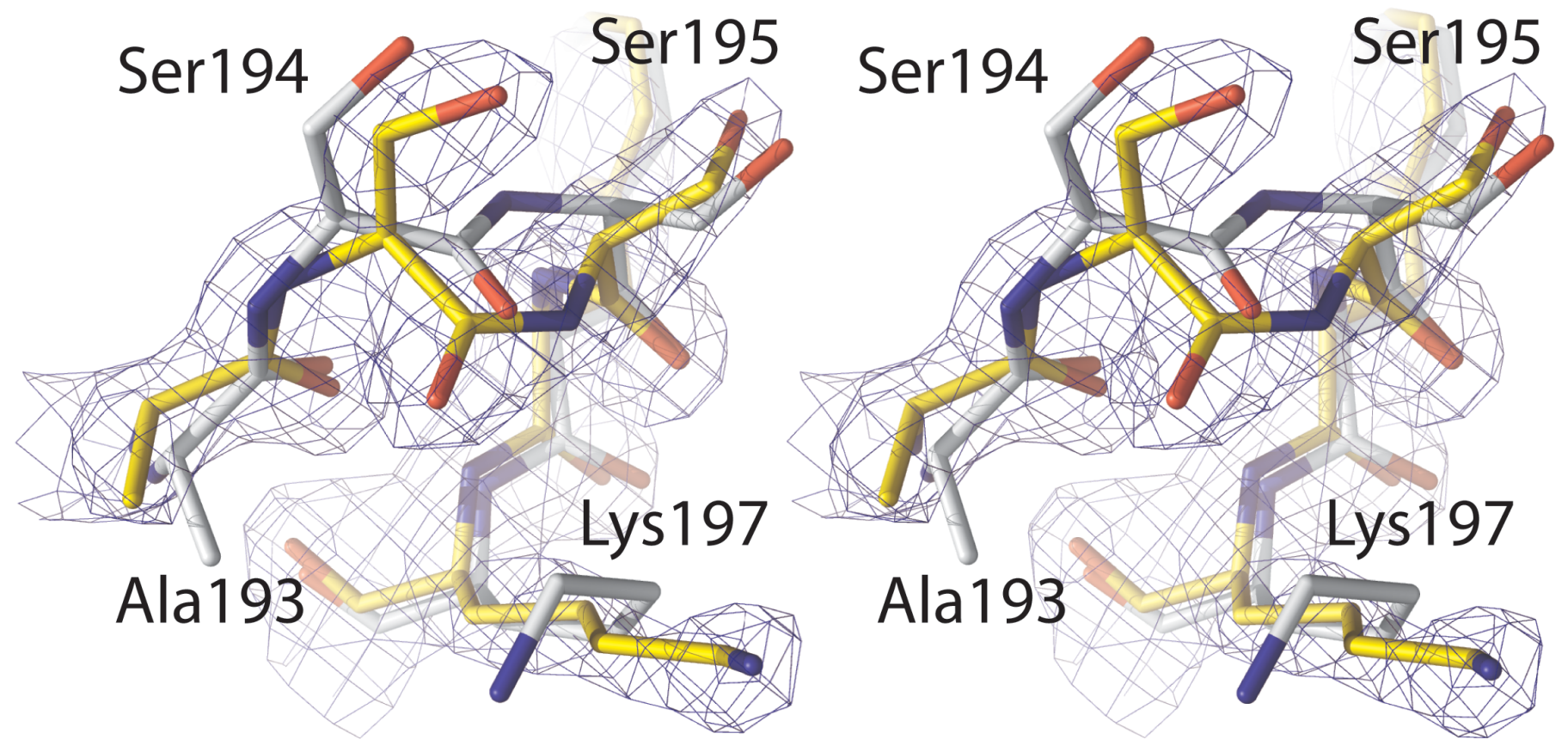


bioRxiv preprint doi: https://doi.org/10.1101/796862; this version posted October 7, 2019. The copyright holder for this preprint (which was not certified by peer review) is the author/funder, who has granted bioRxiv a license to display the preprint in perpetuity. It is made available under

A aCC-BY-NC-ND 4.0 International license.

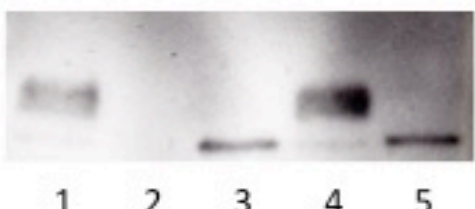

1: OMCP

2: Mock

3: (N12Q) OMCP

4: (N88Q) OMCP

5: (N12Q/N88Q) OMCP

B

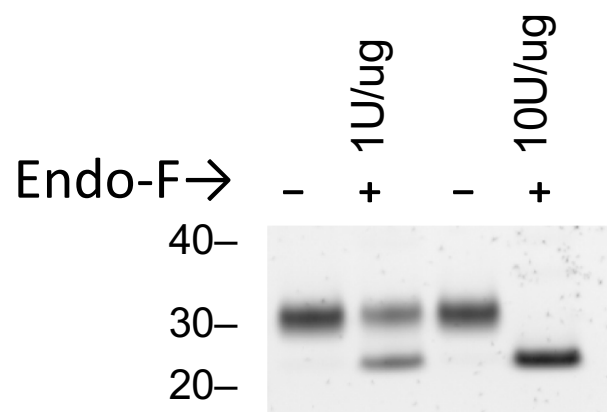

